Different Roles of Shared and Vertical Leadership in Promoting Team Creativity:

Cultivating and Synthesizing Team Members' Individual Creativity

\author{
Wei He \\ Nanjing University \\ E-mail:whe@nju.edu.cn \\ Po Hao \\ Northwest University (China) \\ Xu Huang \\ The Hong Kong Baptist University \\ Li-Rong Long \\ Huazhong University of Science and Technology \\ Nathan J. Hiller \\ Florida International University \\ Shao-Long Li \\ Wuhan University
}

Paper accepted at Personnel Psychology

Version of Record is at: doi: 10.1111/peps.12321.

First published online: February 26, 2019. Print version forthcoming (as of May 1, 2019). 


\begin{abstract}
Drawing on the componential model of creativity (Amabile, 1988), we examined how shared leadership and a formally appointed leader's transformational leadership jointly cultivate team creativity in two studies. We conducted an experiment with a sample of 109 undergraduate students (32 teams) enrolled in a business plan competition (Study 1) and a field survey based on multisource, time-lagged data collected from 251 full-time employees working on 64 research and development teams (Study 2). The results from both studies revealed that shared leadership enhanced team members' individual creative self-efficacy and individual creativity, which in turn improved team creativity. Moreover, the results from Study 2 showed that a formally appointed leader's use of different transformational leadership behaviors had different impacts on individual and team creativity. Individual-focused transformational leadership strengthened the positive effect of shared leadership on team members' average individual creativity, whereas group-focused transformational leadership facilitated the translation of teams with high average individual creativity into teams with high levels of team creativity. The theoretical and practical implications of the findings are discussed.
\end{abstract}

Keywords: Shared leadership; team creativity; individual-focused transformational leadership; group-focused transformational leadership 


\section{Different Roles of Shared Leadership and Vertical Leadership in Promoting Team Creativity: Cultivating and Synthesizing Team Members' Individual Creativity}

The ability to continually generate creative ideas, solutions, products, and services is critical for organizations to adapt to an environment characterized by rapid technological change, fierce global competition, and high economic uncertainty (D’Aveni, 2010). To meet the need for speedy and complex change and creation, firms increasingly rely on work teams rather than individual employees to generate novel and useful ideas and solutions (Shalley \& Perry-Smith, 2008). This reliance has led to a burgeoning scholarly interest in the driving forces of and processes leading to team creativity, which is defined as "the production of novel and useful ideas concerning products, services, processes and procedures by a team of employees working together" (Shin \& Zhou, 2007, p. 1710).

One of the most crucial factors related to team creativity is leadership (Gilson, Litchfield, Lim, \& Gilson, 2015). For instance, prior research has revealed that leaders' transformational behaviors are effective in promoting team creativity in both research and development (R\&D) teams (Chen, Farh, Campbell-Bush, Wu, \& Wu, 2013) and other functional work groups in organizations (Hu, Ergon, Jiang, Bauer, Liu, 2018; Zhang, Tsui, \& Wang, 2011). As with much of the literature examining leadership effects, the extant research examining leadership effects on team creativity has almost exclusively focused on the top-down influence of vertical leadership — that is, the influence process initiated by an individual leader, typically formally appointed. This line of research has also exclusively focused on the team-level mechanisms of positive team processes or emergent team states, such as knowledge sharing, information exchange, and collective efficacy (Chen et al., 2013; Gong, Kim, Lee, \& Zhu, 2013; Shin \& Zhou, 2007), in accounting for the positive influences of vertical leadership on team creativity.

However, another manifestation of leadership — shared leadership — may also be particularly important in understanding team creativity. Shared leadership, as a bottom-up 
form of leadership, is an emergent team phenomenon in which multiple team members enact leadership functions and roles with the objective of achieving team goals (D'Innocenzo, Mathieu, \& Kukenberger, 2016; Hiller, Day, \& Vance, 2006; Pearce \& Conger, 2003). In contrast to vertical leadership, which assumes that leadership is the property of an individual with authority or power over others, shared leadership is a function or property of team members' collective influence (Avolio, Jung, Murray, \& Sivasubramaniam, 1996; Contractor, DeChurch, Carson, Carter, \& Keegan, 2012; Morgeson, DeRue, \& Karam, 2010).

Whereas vertical leadership influences team creativity mainly through its top-down implications for enhancing team processes or states (Gong et al., 2013; Shin \& Zhou, 2007), shared leadership is more likely to enhance team creativity through its bottom-up implications for cultivating more creative individuals on the team. Indeed, prior research has suggested that the context of shared leadership is conducive to team members' engagement in self-development and self-learning behaviors (Hooker \& Csikszentmihalyi, 2003; Liu, Hu, Li, Wang, \& Lin, 2014), providing the feedstock for individual creativity. Team members' high levels of individual creativity may not, however, necessarily lead to high team creativity when individual members' creative efforts and outcomes cannot be integrated and synthesized (Harvey, 2014). Disconnected individual creative endeavors may even harm team creative processes due to potential conflicts among creative individuals (Farh, Lee, \& Farh, 2010). This issue has led to an unclear yet underexamined relationship between shared leadership and team creativity, which is the central focus of our research.

In this research, we take into account both shared leadership and vertical leadership in an attempt to gain more nuanced insights into the effect of shared leadership on team creativity. Drawing on the componential model of creativity (Amabile, 1988), which explains how contextual factors in organizations promote small-group (team) creativity by influencing individuals' task-related knowledge and skills, creativity-relevant capacity, and motivation to 
perform a collective task, we suggest that in the context of shared leadership, the sharing of influence processes strengthens team members' creativity-relevant capacity, particularly creative self-efficacy (i.e., individual self-efficacy to engage in creative explorations), and in turn cultivates individual creativity. At the team level, we argue that shared leadership enables work teams to develop more creative individuals - the team's valuable resources in creative tasks that are vital inputs for team creativity.

We further investigate how a formally appointed leader's individual-focused transformational leadership (TFL) behaviors_-aiming to empower employees to develop their full potential and enhance their skills, abilities, and self-concept perceptions (Wang \& Howell, 2010) — and group-focused TFL behaviors — communicating the importance of group goals, developing shared values and beliefs, and inspiring unified effort to achieve group goals (Wang \& Howell, 2010)—produce different mechanisms and pathways of action in ultimately influencing team creativity. We suggest that individual-focused TFL facilitates the influence of shared leadership on team members' individual creativity by strengthening team members' creative self-efficacy, whereas group-focused TFL facilitates the translation of high levels of individual creativity into high team creativity by strengthening team members' motivation to engage in the team's collective creative task (Amabile, 1988).

Insert Figure 1 about here

Our overall research model is depicted in Figure 1. We seek to make several interrelated contributions to the leadership and team creativity literatures. First, we extend the scholarly understanding of the role that leadership plays in team creative processes by revealing the influence of shared leadership. Previous research has extensively demonstrated that team creativity is influenced by formal team leaders' downward influence (i.e., vertical leadership) via different positive team processes or emergent team states, and our research 
advances this stream of research by revealing that team creativity is also influenced by collective leadership activities shared by team members themselves, at least in part through the cultivation of more creative individuals on a team. Additionally, our research provides an integrative perspective for understanding the joint influences of shared leadership and vertical leadership on team outcomes. In particular, our examination of the different moderating roles played by individual- and group-focused TFL behaviors in the relationship between shared leadership and team creativity contributes to the team leadership literature by providing a more complete understanding of how various forms of leadership may work together to drive team outcomes (e.g., Morgeson et al., 2010; Wang, Waldman, \& Zhang, 2014; Yammarino, Salas, Serban, Shirreffs, \& Shuffler, 2012). Finally, our dual-stage mediating model linking shared leadership with team creativity sheds new light on the team creative process by underscoring the crucial roles of both cultivating (Woodman, Sawyer, \& Griffin, 1993; Taggar, 2002) and synthesizing (Harvey, 2014; Hargadon \& Bechky, 2006) team members' individual creativity. Our findings also suggest that vertical leadership (i.e., transformational leadership) plays a key role in bridging multiple creative episodes occurring at different levels (i.e., individual and team) in an organization.

\section{Theory and Hypotheses}

\section{Conceptualization of Shared Leadership}

Shared leadership has been conceptualized in different ways (e.g., Carson, Tesluk, \& Marrone, 2007; Nicolaides, LaPort, Chen, Tomassetti, Weis, Zaccaro, \& Cortina, 2014; Pearce \& Conger, 2003; Yammarino et al., 2012). Central to shared leadership's conceptualization are the leadership roles and functions to be shared among team members (Wang et al., 2014). One approach to conceptualizing shared leadership is process-oriented, which focuses on the dynamic process through which multiple team members exhibit leadership influences by enacting various leadership roles and functions. For instance, 
researchers have conceptualized shared leadership as a dynamic process whereby team members display (coordinated and/or dispersed) behaviors performing two major leadership functions - task-oriented and relationship-oriented functions (Hiller et al., 2006) — or exhibit typical leadership behaviors distributed or dispersed among team members such as directive leadership (e.g., Ensley, Hmieleski, \& Pearce, 2006), empowering leadership (e.g., Pearce \& Sims, 2002), and transactional leadership (Pearce, Yoo, \& Alavi, 2004), and TFL (e.g., Boies, Lvina, \& Martens, 2010). Another approach to conceptualizing shared leadership is state-oriented, which focuses on the emergent team state of reciprocal reliance and shared influence among team members (e.g., Carson et al., 2007; Chiu, Owens, \& Teslin, 2016; Liu et al., 2014). For instance, Carson and colleagues (2007) defined shared leadership as "an emergent team property that results from the distribution of leadership influence across multiple team members" (p. 1218).

Integrating these two approaches, we conceptualize shared leadership as an emergent team phenomenon in which multiple team members take on leadership roles to influence others whenever appropriate to achieve collective goals. Central to our conceptualization of shared leadership is the emergent team phenomenon - a multidirectional, reciprocal influence process simultaneously initiated by multiple team members; that is, team members not only lead others but also follow the lead of others. The underpinnings of such a team phenomenon are the leadership functions and roles being shared among multiple team members (Wang et al., 2014). Therefore, our conceptualization not only involves the team process of team members enacting different leadership roles and functions but also captures the state of the team's overall capacity for collective mutual influence. On the basis of this conceptualization, we next theorize how shared leadership increases team members' individual creativity and team creativity.

\section{Shared Leadership and Team Members' Individual Creativity}


The componential model of creativity (Amabile, 1988) is the most widely cited theory of creativity in the organizational context (Anderson, Potočnik, \& Zhou, 2014). This model proposes that three individual-level components (i.e., intrinsic motivation to perform a task, skills in the task domain, and creativity-relevant capacity) influence individual creativity and suggests that this individual creative process can be extended to the creative process of small groups or teams. This model also proposes how these components are influenced at different levels by the external environment, such as leadership (Amabile, 1988).

The extant research (e.g., Chen, Sharma, Edinger, Shapiro, \& Farh, 2011; Gong, Huang, \& Farh, 2009; Shin \& Zhou, 2003; Zhang \& Bartol, 2010) has demonstrated that a formally appointed team leader's vertical leadership (e.g., TFL and empowering leadership) facilitates individual creative processes by enhancing both intrinsic motivation and creativity-relevant capacity (e.g., creative self-efficacy). At the team level, vertical leadership has also been found to promote team creativity by enhancing the team's collective capacity and skills in creativity management. For instance, Zhang and colleagues (2011) revealed that formal leaders' transformational behaviors are positively related to group creativity by strengthening the creativity-relevant team process of knowledge sharing and the emergent team state of collective efficacy among group members.

Building on the componential model of creativity (Amabile, 1988) and extending prior research findings regarding the influence of vertical leadership on individual creativity, we suggest that shared leadership is also likely to promote team members' individual creativity by enhancing one's creativity-relevant capacity, particularly individual creative self-efficacy, a motivational construct reflecting the degree to which individuals view themselves as capable (e.g., knowledgeable and skillful) of producing creative outcomes at work (Tierney \& Farmer, 2002). 
We suggest that a team context with a high level of shared leadership is likely to enable team members to gain diverse experience in accomplishing tasks and resolving problems through their mutual influences, enhancing their confidence in creative endeavors accordingly. Specifically, by sharing some aspects of leadership responsibilities and roles, team members engage in self-development activities and must think, judge, and behave as the formal leader does. More importantly, team members must influence diverse others to accomplish their proposed goals and deal with challenging work-related problems (Carson et al., 2007). These experiences may increase team members' confidence in generating new knowledge and skills to resolve problems and influence others. Meanwhile, when following the lead of other members, individuals engage in self-learning activities to receive, follow, and absorb diversified perspectives of carrying out different parts of teamwork from other members who are enacting leadership roles (Liu et al., 2014). The more diversified perspectives one learns at work, the more competent one will be in creative thinking (Gong et al., 2009). To synthesize, team members' creative self-efficacy will be enhanced in a team context associated with shared leadership because such a context is conducive to individuals' development of competence, acquisition of diversified perspectives, and experience with creative thinking (Gong et al., 2009; Hooker \& Csikszentmihalyi, 2003).

In turn, increased creative self-efficacy is likely to facilitate individual creativity at work by facilitating creativity-relevant processes (Amabile, 1988). Specifically, employees with higher levels of creative self-efficacy tend to engage in a more open-minded work style that is conducive to generating novel and useful ideas. Moreover, creative explorations require trial-and-error experimentation in unknown situations and the willingness to learn from such efforts (Tierney \& Farmer, 2011). Employees with high creative self-efficacy can meet these requirements and offset obstacles inherent to creative engagement because efficacious individuals tend to use approaching and self-regulative learning strategies in the 
process of creative engagement (Gong et al., 2009). Integrating these theoretical rationales, we propose a mediating relationship between shared leadership and individual creativity via creative self-efficacy.

\section{Hypothesis 1a: Shared leadership has an indirect and positive effect on team members' individual creativity via individual creative self-efficacy.}

\section{Shared Leadership and Team Creativity}

The componential model of creativity (Amabile, 1988) suggests that the small-group (team) creative process is similar to the individual creative process. Thus, the influence of shared leadership on team members' individual creativity provides a microfoundation for its influence on the team creative process. At the team level, increases in individual creative self-efficacy associated with shared leadership will accumulate into a high level of team average creative self-efficacy, which we define as a formative construct reflecting the mean level of team members' individual belief about one's ability to effectively perform creative requirements and complete creative tasks (Bandura, 1986; Tierney \& Farmer, 2002). In a similar vein, increases in team members' individual creativity will accumulate into a high level of team average individual creativity, which is a formative construct reflecting the mean level of team members' individual creative outputs (Gong et al., 2013). According to the componential model of creativity (Amabile, 1988), team members' average creative self-efficacy can be seen as the team's accumulated capacity and skills for creative thinking, which should lead to an increased mean level of team members' individual creative outputs (i.e., team members' average individual creativity). Therefore, extending the effects proposed in Hypothesis 1a to the team level, we suggest a team-level mediating relationship between shared leadership and team members' average individual creativity via members' average creative self-efficacy. 
Hypothesis 1b: Shared leadership has an indirect and positive effect on team members' average individual creativity via team members' average creative self-efficacy.

When a team's average individual creativity is enhanced by shared leadership, the team as a whole has a large pool of resources in the task domain (i.e., people with sufficient expertise, skill, and novel ideas to perform the work creatively), which is an essential contributing factor for team creativity (Amabile, 1988). According to the componential model of creativity, a team's average individual creativity will have a positive effect on team creativity by influencing the effectiveness of two vital stages involved in team creative processes: collective goal setting and idea testing and implementation.

First, high average individual creativity on a team facilitates the collective goal-setting process by providing sufficient and diverse starting points or directions for creating novel and useful solutions for a team project (Amabile \& Pratt, 2016). Second, high average individual creativity can improve a team's overall efficiency in evaluating and testing the ideas presented by individuals and fully developing one of those ideas through frequent communications and interactions among multiple creative thinkers on the team (Gilson \& Shalley, 2004), as well as through a supportive team climate for creativity generated by the creative acts of team members (Gong et al., 2013). Consistent with our theorization, past empirical studies have demonstrated this causal effect of members' average individual creativity on team creativity, both in a well-controlled experimental setting (Girotra, Terwiesch, \& Ulrich, 2010) and in more generalized field settings (Chen et al., 2013; Gong et al., 2013; Taggar, 2002). Taken together, we predicted the following relationship:

Hypothesis 2: Shared leadership has an indirect and positive effect on team creativity via team members' average creative self-efficacy and average individual creativity on a team.

\section{The Moderating Role of Vertical Leadership}


Even though both shared leadership (Hoch, 2013) and vertical leadership (e.g., Zhang et al., 2011) have demonstrated associations with team creativity independently, their interactive effects have not been examined. However, there is prior research (i.e., Gong et al., 2013; Shin \& Zhou, 2007) and good reason to assert that formally appointed leaders' vertical leadership behaviors could act as a contextual catalyst facilitating the transformation of shared leadership to team members' individual creativity and to team creativity. In the present research, we focus on TFL, a widely examined form of formally appointed vertical leadership. The significance of TFL in producing positive individual, team, and organizational outcomes is well recognized (Bass, 2008) and has been linked to both individual and team creativity (e.g., Shin \& Zhou, 2003; Chen et al., 2013; Zhang et al., 2011). Given that the large and broad TFL construct encompasses such a large set of different behaviors (Kark \& Shamir, 2002), a number of scholars have more recently suggested and demonstrated that one valid and useful way to partially disentangle the construct is by considering behaviors directed toward the group vs. behaviors directed toward individuals-leading to a conceptual distinction between group-focused TFL (i.e., idealized influence and inspirational motivation) and individual-focused TFL (i.e., intellectual stimulation and individualized consideration) (e.g., Chun, Cho, \& Sosik, 2016; Wang \& Howell, 2010; Wu, Tsui, \& Kinicki, 2010). We suggest that these types of TFL play different roles in the mediation relationship between shared leadership and team creativity via team members' average creative self-efficacy and members' average individual creativity.

\section{Individual-Focused Transformational Leadership}

We contend that individual-focused TFL behaviors enacted by the formally appointed leader will facilitate the relationship between shared leadership and team members' average individual creativity by strengthening shared leadership's influence on members' average creative self-efficacy. First, engaging in shared leadership enables members to gain diverse 
expertise, perspectives, and experiences that are conductive to the enhancement of creative self-efficacy. Individual-focused TFL strengthens this learning process because the formally appointed leader's encouragement and expectation for individual creative endeavors and outputs (i.e., intellectual stimulation) legitimizes members' creative learning process, which results from the lateral social interactions involved in leading and following others in the context created by shared leadership (Tierney \& Farmer, 2002).

In addition, exploring new ideas, products, and work methods at work is quite risky (McAllister, Kamdar, Morrison, \& Turban, 2007), so the development of employees' efficacious perceptions of engaging in risky creative endeavors at work requires a safe environment (Bandura, 1997). Although team members can develop their creative self-efficacy during their social interactions by sharing leadership roles, the formally appointed leader is still critical in creating a safe environment to further strengthen members' self-perceptions about abilities to engage in unknown and risky explorations. Specifically, by providing resources and support for individuals' exploratory behaviors (Aragón-Correa, García-Morales, \& Cordón-Pozo, 2007) and forgiving individuals' failures or wrong-doings during their proactive explorations in broader work areas (Avolio \& Gibbons, 1988), team leaders' individual-focused TFL behaviors will create an environment for employees' development of creative self-efficacy. In other words, the formally appointed team leader's individual-focused TFL is likely to have an amplifying effect when paired with shared leadership to increase team members' creative self-efficacy.

Taken together, we argue that high individual-focused TFL will magnify the positive relationship between shared leadership and team members' average creative self-efficacy and will in turn strengthen the indirect relationship between shared leadership and team members' average individual creativity via members' average creative self-efficacy. We thus propose the following hypotheses: 
Hypothesis 3a: A formally appointed leader's individual-focused transformational leadership moderates the relationship between shared leadership and team members' average creative self-efficacy such that the relationship will be more positive when individual-focused transformational leadership is high rather than low.

Hypothesis 3b: A formally appointed leader's individual-focused transformational leadership moderates the indirect relationship between shared leadership and team members' average individual creativity via team members' average creative self-efficacy such that the indirect relationship will be more positive when individual-focused transformational leadership is high rather than low.

\section{Group-Focused Transformational Leadership}

There is a theoretical debate about how team members' individual creativity can be translated into team creativity. Although some researchers have regarded team creativity as merely a simple summation of team members' individual creativity (Pirola-Merlo \& Mann, 2004; Taggar, 2002), others have argued that team creativity depends on, but is not a simple summation of, team members' individual creativity (Chen et al., 2013; Woodman et al., 1993). Specifically, individual creativity is associated with how individuals generate novel knowledge about and ways to perform work-related tasks and achieve individual goals and outputs, whereas team creativity reflects the production of novel and useful knowledge in the processes of performing team tasks and attaining team goals and outputs. Thus, the domain-specific element of what constitutes novelty and usefulness differs between individual creativity and team creativity (Ford, 1996). According to Gong et al. (2013), the average individual creativity of a team merely reflects the mean level of the team members' individual creativity, yet individual members may differ substantially in their domains of creativity, and their creative outputs may cause task-related conflicts. Because a team's collective goal/outcome is not a simple summation of team members' individual work outcomes, high average individual creativity on a team provides only one basis for team creativity. The impact of average individual creativity depends on the transformation of diverse creative perspectives from team members into a shared understanding that is unique 
to the team's objective (Hargadon \& Bechky, 2006). In other words, team creativity relies on synergic forces that help translate team members' individual creativity into team creativity (Harvey, 2014).

We argue that a formally appointed team leader's vertical influences associated with group-focused TFL behaviors facilitate the translation of a team's average individual creativity into team creativity. In particular, we focus on the central role of group-focused TFL in the translation of team members' individual creativity into team creativity by providing a centralizing and focusing force for team members' diverse input, effort, and motivation (e.g., Shin \& Zhou, 2007). The behaviors that compose the group-focused TFL construct are idealized influence (i.e., a formal leader's pro-social role modeling behaviors that prioritize the collective goal, such as challenging the status quo and articulating a compelling vision) and inspirational motivation (i.e., energizing followers by articulating an ambitious goal) and are sometimes referred to as leader charisma (Kark \& Shamir, 2002). These group-focused behaviors help reinforce a team's shared vision, mission, and common goals, which can strengthen employees' collective identification and their motivation to contribute to a collective purpose (van Knippenberg \& Sitkin, 2013). Thus, in particular, a team context created by a formal leader's group-focused transformational behaviors supports team creative processes (Gilson \& Shalley, 2004), which has been demonstrated to be a key mechanism in transforming team members' individual creativity into team creativity (Gong et al., 2013).

According to the componential model of creativity (Amabile, 1988), we argue that group-focused TFL can facilitate a team's creative processes underlying the transformation of average individual creativity on a team into team creativity by strengthening team members' motivation to perform a collective creative task. Specifically, both idealized influence and inspirational motivation underscore team values and collective goals by articulating a 
compelling vision and setting ambitious team objectives (Wu et al., 2010), motivating team members to be more other-oriented and more collaborative during their own creative explorations (Wang \& Howell, 2010) and thus facilitating the integration of team members' diversified perspectives into a shared understanding specific to the collective goal of the team (Harvey, 2014). In other words, team members' individual creative outputs will be more consistent with the team's collective goal and less in conflict with each other when the team's formally appointed leader has a high level of group-focused transformational behaviors (Taggar, 2002). When a team's formally appointed leader has a low level of group-focused transformational behaviors, however, team members may lack strong direction in their own creative explorations, causing team members' individual creativity (even at high levels in general) to be disconnected from one another and thus more difficult to integrate and synthesize. Moreover, when facing various potential novel solutions for a team project produced by team members, group-focused transformational leaders who have strong collective orientations and who frequently challenge the status quo will be more effective and efficient in selecting, retaining, and implementing the best solutions for the team project (Pirola-Merlo \& Mann, 2004).

Taken together, a formally appointed leader's group-focused TFL behaviors strengthen collective effort, goals and mission and render the team more effective in selecting and implementing creative ideas from team members, thereby facilitating the transformation of team members' individual creativity into team creativity and strengthening the dual-stage, mediating relationship between shared leadership and team creativity via team members' average creative self-efficacy and average individual creativity. We thus propose the following moderated mediation hypotheses.

Hypothesis 4a: A formally appointed leader's group-focused transformational leadership moderates the relationship between team members'average individual creativity and team creativity such that the indirect relationship will 
be more positive when group-focused transformational leadership is high rather than low.

Hypothesis 4b: A formally appointed leader's group-focused transformational leadership moderates the indirect relationship between shared leadership and team creativity via team members' average creative self-efficacy and average individual creativity such that the indirect relationship will be more positive when group-focused transformational leadership is high rather than low.

The above theorization suggests that a formally appointed team leader's individual-focused TFL behaviors and group-focused TFL behaviors facilitate the team-level relationship between shared leadership and team creativity via team members' average creative self-efficacy and members' average individual creativity by exhibiting different influences: whereas individual-focused TFL strengthens the effect of shared leadership on team members' average individual creativity as mediated by members' average creative self-efficacy, group-focused TFL plays a vital role in transforming high average individual creativity on the team into high team creativity. Despite the independent roles they play in different stages throughout this team-level process linking shared leadership with team creativity, we expect a synergetic, moderating effect of individual-focused TFL and group-focused TFL on this relationship and suggest that this relationship will be most positive when both individual-focused TFL and group-focused TFL are high. We thus propose the following moderated mediation hypothesis.

Hypothesis 5: A formally appointed leader's individual-focused transformational leadership and group-focused transformational leadership jointly moderate the indirect relationship between shared leadership and team creativity via team members' average creative self-efficacy and average individual creativity such that the indirect relationship will be most positive when both individual-focused transformational leadership and group-focused transformational leadership are high.

\section{Research Overview}

We tested our theoretical model in two studies. In Study 1, we conducted an experiment examining the effects of shared leadership on team members' individual creativity 
and team creativity (Hypotheses 1-2) among university students engaged in a business plan competition. In Study 2, we tested all the team-level predictions of our conceptual model in a multisource, time-lagged field sample of R\&D teams. In addition to applying different research methodologies, we utilized different approaches to operationalizing shared leadership in two studies to enhance the internal validity of our research findings. Specifically, in Study 1, we manipulated shared leadership by forcing every team member to take on the leadership role and to display influences to other members in different stages of an experiment project. In Study 2, we measured shared leadership by assessing the extent to which team members collectively enacted specific leadership roles/functions in their everyday work.

\section{Study 1}

\section{Participants and Procedures}

We recruited 130 undergraduate business students from a Chinese university to participate in a four-week business plan competition for which they could receive extracurricular credits needed to complete their degree. The participants were randomly assigned to one of 32 four-person teams (with two five-person teams). To motivate performance, we advertised and set a monetary bonus for the top six teams (i.e., one first-prize team would be rewarded 1,000 Chinese yuan, two second-prize teams would be rewarded 600 Chinese yuan each, and three third-prize teams would be rewarded 300 Chinese yuan each). The participants were told both in writing and verbally that creativity would be a critical factor in the evaluation of their business plans. The 32 teams were then randomly and equally divided into two experimental manipulation conditions: high shared leadership instruction and low shared leadership instruction.

Before the competition started, the participants were informed about the following procedure and the requirements of the business plan competition. The business plan was 
divided into four major tasks over the four weeks of competition. At the end of each week, the teams submitted a weekly report summarizing their steps and the progress they achieved in relation to the corresponding tasks for each week: (1) idea generation about possible businesses, (2) business mode creation (i.e., mapping out how this business could generate revenues and profit), (3) strategic analysis (i.e., developing a marketing strategy), and (4) writing up the business plan (i.e., integrating all the prior weeks' work and adding a detailed financial analysis). To ensure sufficient social interaction among team members during each of the four stages, we instructed the team members to engage in three face-to-face discussions per week. As part of receiving full credit for the business plan and being eligible for the winning prizes, the teams were asked to document the time, location, participating members, and main content of every meeting in their weekly reports. After the full business plan was submitted at the end of Week 4, the participants completed a questionnaire measuring creative self-efficacy and the creativity of each team member. Twenty-one participants withdrew before the final competition phase when the project plans were presented, resulting in a final sample of 109 participants $\left(M_{\mathrm{age}}=18.67\right.$ years, $77.6 \%$ female), with each of the remaining 32 groups having at least 3 members.

\section{Manipulation and Measures}

Shared leadership manipulation. We manipulated shared leadership by giving different instructions to the teams about the structure of their teams. For teams in the low shared leadership condition, an experimenter-chosen team member (randomly selected) was asked to lead all four subtasks throughout the whole four weeks. For teams in the high shared leadership condition, we asked the formal leader, who was randomly appointed, to lead the first task (i.e., idea generation) in the first week; for the remaining three tasks, each week's task should be led by different team members (for teams with only three members, one team member could lead for two weeks). In both conditions, instructions were given to each team 
member before the beginning of Week 1 . The instructions explained the responsibilities of the appointed leaders, such as planning and organizing meetings, coordinating the team's efforts, making task and process decisions, and resolving disagreements.

For the following scales, we used the back-translation process for all the items to ensure the content validity of Western scales in the Chinese context (Brislin, 1986).

Creative self-efficacy. The team members were asked to recall their competition experiences in the past four weeks and report their own perceptions of creative self-efficacy during this process using three items developed by Tierney and Farmer (2002). These three items were "I have confidence in my ability to solve problems creatively," "I feel that I am good at generating novel ideas," and "I have a knack for further developing the ideas of others." These three items were rated on a five-point Likert scale $(1=$ very strongly disagree, $5=$ very strongly agree). The Cronbach's alpha for these three items was .81 .

At the team level, we averaged all team members' scores for individual creative self-efficacy as a measure of the team's average creative self-efficacy.

Individual creativity. Following prior experimental studies on creativity (e.g., Taggar, 2002), we asked the team members to rate each other's individual creativity during the whole four-week process of the competition. Individual creativity was measured using a four-item, short-version scale adapted from the scale developed by Zhou and George (2001). This short-version scale of individual creativity was used and validated by Baer and Oldham (2006). A sample item was "This team member can suggest many creative ideas that might improve work conditions at work.” These four items were rated on a five-point Likert scale (1 $=$ very strongly disagree, $5=$ very strongly agree). We averaged all other team members' ratings as an overall measure of the focal member's individual creativity. The interrater and intraclass measures - mean $\operatorname{rwg}_{(j)}$ uniform $=.93$, mean $\operatorname{rwg}_{(j)}$ slightly skewed $=.89, \operatorname{ICC}(1)=.51$, 
$\operatorname{ICC}(2)=.72$-justified aggregation across members (Bliese, 2000). The Cronbach's alpha was .87.

At the team level, following Gong et al. (2013), we averaged all team members' scores for individual creativity as a measure of the team's average individual creativity.

Team creativity. Following prior studies (Zhou \& Oldham, 2001; Shalley, 1991), we asked two strategy management professors who were unaware of our experiment to evaluate the business plan proposals with the criteria of novelty and usefulness. Specifically, the two judges were asked to evaluate both the novelty (i.e., the business idea generated by the team is unique relative to other business ideas or modes existing in the market) and usefulness (i.e., the extent to which the proposed business plan would be useful for starting the business and attracting external investors) of each business plan proposal. Then, the evaluators were asked to give an overall rating for creativity based on the subcriteria of novelty and usefulness $(1=$ not creative at all, $7=$ extremely creative). We checked the interjudge reliability (the extent to which the ratings were consistent) using an intraclass correlation approach and obtained high reliability $(\operatorname{ICC}[2]=.96)$. We also found interjudge agreement (the extent to which the judges assigned the same rating to each solution) to be high $(r=.93)$. These results suggested that the two judges showed adequate agreement on their evaluations of the 32 business plan proposals. Thus, we averaged the judges' ratings to create one overall creativity score for each team.

Manipulation check. We utilized two methods to check the validity of the shared leadership manipulation. First, we checked every team's weekly reports in which the name of leader who was in charge of that particular week's subtask was reported. According to the weekly reports, members in the high shared leadership condition rotated their task leadership roles across the four weeks, whereas teams in the low shared leadership condition had the formal leaders lead all four subtasks throughout the four weeks, indicating that the teams followed our instructions precisely when working on their business plans. 
Second, and most importantly, at the end of the experiment, we asked the participants to recall their team members' performance during the four-week competition and to complete the shared leadership measures described below. Drawing from previous social network approaches to measuring shared leadership (Carson et al., 2007; Liu et al., 2014), every team member was asked to rate each of his/her peers on the following question: "To what degree does your team rely on this individual for leadership?" $(1=$ not at all, to $5=$ to a very great extent). We then calculated network density, which reflects the total sum of leadership behaviors displayed by all the team members rated by their peers on a team (Mayo, Meindl, \& Pastor, 2003). Participants in the high shared leadership condition $(M=3.83, S D=.72)$ rated their teams as more laterally structured and the total influence of the team members as stronger than participants in the low shared leadership condition $(M=3.41, S D=.33): t(30)$ $=2.16, p<.05)$. These results further indicate that our manipulation was effective in producing high and low levels of shared leadership.

\section{Results}

The means, standard deviations, reliabilities, and correlations are presented in Table 1. Before testing the mediation relationships, we first conducted a set of analyses of variance (ANOVAs) to explore the main effects of shared leadership on individual creative self-efficacy and individual creativity. The results suggested that participants on the high shared leadership teams reported significantly higher levels of creative self-efficacy than participants on the low shared leadership teams $\left(F=5.98, p<.05, M s=3.94\right.$ vs. $3.64, \eta^{2}$ $=.05)$. In addition, participants on high shared leadership teams exhibited significantly higher levels of individual creativity than participants on low shared leadership teams $(F=9.39, p$ $<.01, M s=4.30$ vs. $\left.3.99, \eta^{2}=.08\right)$. At the team level, the ANOVA results suggested that teams in the high shared leadership condition reported significantly higher levels of average creative self-efficacy $\left(F=4.21, p<.05, M s=3.91\right.$ vs. $\left.3.65, \eta^{2}=.12\right)$, average individual 
creativity $\left(F=4.26, p<.05, M s=4.28\right.$ vs. $\left.4.02, \eta^{2}=.12\right)$, and team creativity $(F=11.42, p$ $<.01, M s=4.59$ vs. $\left.3.66, \eta^{2}=.28\right)$ than teams in the low shared leadership condition. These results suggest that shared leadership has significant and positive effects on both individual creativity and team creativity.

To demonstrate the mediating relationships we proposed in Hypotheses 1 and 2, we ran two independent path-analytic models using Mplus 7.4 (Muthén \& Muthén, 2017). Table 2 presents the results of the individual-level path-analytic model (see Model 1: testing H1a) and the team-level path-analytic model (see Model 2: testing H1b and H2). As shown in Model 1, shared leadership had a positive effect on individual creative self-efficacy (estimate $=.30, p=.01$ ), which further had a positive effect on individual creativity (estimate $=.38, p$ $=.00)$ when controlling for the direct effect of shared leadership on individual creativity (estimate $=.19, p=.03)$. To test the statistical significance of indirect effects, we used the model constraint feature in Mplus to estimate confidence intervals for the hypothesized effects (Muthén \& Muthén, 2017). Bootstrap results with 20000 replications revealed that the indirect effect of shared leadership on individual creativity via individual creative self-efficacy was significantly positive (estimate $=.11,95 \% \mathrm{CI}=[.026, .237])$. Thus, Hypothesis 1a was supported.

At the team level, the results of Model 2 showed that shared leadership had a positive effect on a team's average creative self-efficacy (estimate $=.26, p=.04)$, which further had a positive effect on the team's average individual creativity (estimate $=.61, p=.00$ ) when controlling for the direct effect of shared leadership on average individual creativity (estimate $=.10, p=.35)$. Bootstrap results with 20000 replications revealed that the indirect effect of shared leadership on team members' average individual creativity via average creative self-efficacy was significantly positive (estimate $=.16,95 \% \mathrm{CI}=[.013, .398])$. These results together provided support for Hypothesis $1 \mathrm{~b}$. With respect to the outcome of team creativity, 
the regression results in Model 2 showed that shared leadership had a significant direct and positive effect on team creativity (estimate $=.76, p=.01$ ). The influences of team members' average creative self-efficacy (estimate $=.42, p=.39$ ) and average individual creativity (estimate $=.27, p=.59)$ on team creativity were not significant, however. Moreover, bootstrap analyses revealed that the dual-stage indirect effect of shared leadership on team creativity via team members' average creative self-efficacy and average individual creativity was not significant (estimate $=.04,95 \% \mathrm{CI}=[-.087, .340]$ ). Thus, Hypothesis 2 was not supported.

\section{Discussion}

Through an experimental design, Study 1 provided initial evidence for the effect of shared leadership on team members' individual creativity as mediated by individual creative self-efficacy, as well as for the team-level indirect relationship between shared leadership and team members' averaged individual creativity via team members' average creative self-efficacy. However, Hypothesis 2, which proposes a team-level, dual-stage mediating relationship between shared leadership and team creativity via team members' average creative self-efficacy and average individual creativity, was not supported. One possible reason for this nonsignificant relationship is the weak association between team members' average individual creativity and team creativity - a topic that has been of some previous debate in the literature. This finding may then support our argument that average individual creativity on a team does not necessarily translate into team creativity; it may depend upon some other contextual factors. Another possible reason is that the small sample size of the teams $(\mathrm{N}=32)$ lacked statistical power for path analyses demonstrating a dual-stage mediating relationship.

One limitation of Study 1 is associated with the manipulation of shared leadership. To ensure that teams in the high shared leadership condition would create high levels of shared 
leadership within a short period (a month), we instructed team members to rotate the leadership role in different stages throughout the task. As a result, the essence of our manipulation was rotated leadership (Davis \& Eisenhardt, 2011; Erez, Lepine, \& Elms, 2002), which is a particular form of shared leadership (Yammarino et al., 2012). Given that shared leadership also exists in other forms, in Study 2, we sought to replicate the results of Study 1 by examining team-level relationships (i.e., Hypotheses 2-5), which are the core of our research, using a sample of organizationally-based R\&D teams and employing a more direct measure and operationalization of shared leadership.

\section{Sample and Procedure}

\section{Study 2}

We designed a multisource and time-lagged data collection procedure and surveyed 69 R\&D project teams from 18 firms across diverse industries (e.g., automobile, medicine, telecommunication, and electronics) located in the People's Republic of China. All the teams consisted of functionally diverse members, which was a criterion for initial selection into the study. Through conversations with human resource (HR) managers, we confirmed that the primary goal of the R\&D teams in our study was to develop new products, improve existing products, or enhance operational processes for their respective organizations using new technologies and novel techniques.

We chose $R \& D$ project teams as the sample for our research for two main reasons. First, to encourage creativity, managers usually give relatively high levels of work autonomy and flexibility to R\&D employees, suggesting that shared leadership is more likely to emerge (c.f., Carson et al., 2007). Second, engaging in creative processes is the key feature of R\&D teams. The R\&D teams in our sample engaged in core activities such as generating new ideas, searching for novel ideas to create new products, improving the functioning of an old product, creating prototypes, and navigating technology transfer. Notably, in R\&D teams, although 
each individual member needs to exhibit creativity in performing his/her tasks, the creativity of the team depends on the coordination of the creative works of individual members.

At Time 1, 315 team members from $69 \mathrm{R} \& \mathrm{D}$ teams were invited to participate in the survey and were instructed to complete measures of demographic information, shared leadership, creative self-efficacy, and the formally appointed leader's TFL behaviors. We conveyed the academic purpose of our survey, promised a payment of 20 Chinese yuan (approximately 3.27 U.S. dollars) for participation, and guaranteed the confidentiality of individual results. We encouraged all members on every team to participate in our survey. A total of 286 individuals (from all 69 teams) participated and returned completed questionnaires, resulting in a response rate of $90.8 \%$. Two weeks later, at Time 2 , the HR manager from each firm was asked to send questionnaires to the team leaders, who were invited to rate team creativity and their own demographic information. Then, the team leaders were asked to evaluate the team members' individual creativity through an independent version of the questionnaire that listed the names of the employees who participated in the survey two weeks previously. The team leaders also received 20 Chinese yuan for their participation. Sixty-four of the 69 leaders returned completed questionnaires to the researchers via prepaid envelopes, resulting in a $92.8 \%$ response rate from the team leaders.

The final sample consisted of 251 team members from 64 teams. The mean age of these team members was 31 years $(S D=6.24)$, and the mean organizational tenure was six years $(S D=6.97)$. Sixty percent of the sample was male, and $72 \%$ had a bachelor's degree or higher. The mean age of the team leaders was 37 years $(S D=6.82)$, and the mean organizational tenure was 10 years $(S D=7.40)$. The leaders were $73 \%$ male, and $75 \%$ of them had a bachelor's degree or higher. On average, each of the 64 teams had 3.92 members participating in our survey, ranging from 3 to $8(S D=1.07)$.

\section{Measures}


For the scales that were not used in Study 1, we used the same back-translation process to ensure the content validity of Western scales in the Chinese context (Brislin, 1986).

Shared leadership. Shared leadership was measured using the 25-item scale developed by Hiller et al. (2006). This scale includes four subdimensions covering four functions of leadership: planning and organization (PO), problem solving (PS), support and consideration $(S C)$, and developing and mentoring $(D M)$. In our research context, $P O$ reflects the extent to which team members share in setting objectives, such as determining how team resources are allocated for everyone's R\&D work. PO was measured by six items, and a sample item was "How often do team members share in planning how the work gets done?" $P S$ reflects the extent to which team members share in identifying problems in each other's R\&D work and in resolving these problems using collective knowledge and expertise. PS was measured by seven items, and a sample item was "How often do team members share in finding solutions to problems affecting team performance?" $S C$ reflects the extent to which team members provide support to others in their $\mathrm{R} \& \mathrm{D}$ work and encourage others in creative exploration. SC was measured by six items, and a sample item was "How often do team members share in encouraging other members when they're upset?" Lastly, $D M$ reflects the extent to which members share their own knowledge and skills with other team members and learn from others' creative ideas in different R\&D work. DM was measured by six items, and a sample item was "How often do team members share in helping to develop each other's skills." A short introduction was given to participants before these specific items, emphasizing that they should evaluate the frequency with which team members shared the leadership roles/functions described in the items (the full scale is listed in the Appendix). Team members rated the frequency of the activities described using a 7-point Likert scale $(1=$ never; $7=$ always). We used Hiller et al.'s (2006) scale because it emphasizes the 
process-oriented conceptualization of shared leadership, unlike Study 1's state-oriented measure of shared leadership. Moreover, representative items of this scale have been used and validated in recent research on shared leadership (e.g., Chiu et al., 2016; Erkutlu, 2012; Wood, 2005; Wood \& Fields, 2007). In our study, the Cronbach's alpha values for the PO, PS, $\mathrm{SC}$, and DM subdimensions were $.89, .91, .92$, and .91 , respectively.

To test whether the four subdimensions could be aggregated into an integrated construct, we conducted a multilevel confirmatory factor analysis (MCFA). The results indicated that a second-order model (one higher-order factor with four lower-level factors) yielded an acceptable fit to the data $\left(\chi^{2}=536.22, d f=271, \chi^{2} / d f=1.98, R M S E A=.06, T L I\right.$ $=.91, C F I=.92, S R M R($ within $)=.06, S R M R($ between $)=.00)$. Thus, following previous research (Hoch \& Kozlowski, 2014), we aggregated these four dimensions into an overall construct of shared leadership. The Cronbach's alpha for overall shared leadership was .96. Aggregation indices $\left(\right.$ mean $\operatorname{rwg}_{(j)}$ uniform $=.97 ;$ mean $\operatorname{rwg}_{(j)}$ slightly skewed $=.92 ; \operatorname{ICC}[1]=.12$; ICC $[2]=.34)$ supported our treatment of shared leadership as a team-level construct by averaging the team members' individual scores for shared leadership.

Average creative self-efficacy. The employees were asked to assess their creative self-efficacy using the same three-item scale from Tierney and Farmer (2002) that we used in Study 1 . The reliability of this scale was .80 in our study. Following the same approach used in Study 1, we measured each team's average creative self-efficacy by calculating the mean for all team members' scores for individual creative self-efficacy.

Average individual creativity. The formal team leaders were asked to evaluate the team members' individual creativity by focusing on the extent to which they had novel and useful ideas regarding their individualized R\&D work assignment. Individual creativity was measured using the same scale we used in Study 1. The Cronbach's alpha for this scale in our 
study was .90 . Consistent with Study 1, team members' average individual creativity was measured by calculating the mean for all members' individual creativity.

Team creativity. The formal leaders were asked to rate their teams' overall creative performance by focusing on the extent to which the objective team output was novel and useful in relation to the ideal goal or standard for team creative performance previously established by their organizations. Team creativity was measured using a three-item scale developed by Farh et al. (2010) in the Chinese context. These three items were rated on a 5-point Likert scale $(1=$ very strongly disagree, $5=$ very strongly agree $)$. A sample item was “Team output is original and practical." The Cronbach's alpha for this variable was .77 in our study.

Transformational leadership. Transformational leadership was measured with a twenty-four-item scale derived from the Multifactor Leadership Questionnaire (MLQ5x) (Bass \& Avolio, 1995). ${ }^{1}$ In line with recent research suggesting two higher-order factors (e.g., Wu et al., 2010), two dimensions (i.e., individualized consideration and inspirational stimulation) of the TFL scale were averaged and aggregated to the team level to measure the individual-focused TFL of the team leader. A sample item for individualized consideration was "My leader spends time teaching and coaching me", and a sample item for individualized stimulation was "My leader gets me to look at the task from many different angles".

Another two dimensions (i.e., idealized influence and inspirational motivation) of the TFL scale were averaged and aggregated at the team level to measure the group-focused TFL of the team leader. A sample item for idealized influence was "Our group leader emphasizes the importance of having a collective sense of mission," and a sample item for inspirational motivation was "Our group leader expresses his/her confidence that we will achieve our goals." The items were rated on a 5 -point Likert scale $(1=$ very strongly disagree, $5=$ very

\footnotetext{
${ }^{1}$ We bought the rights to use this scale from Mind Garden Inc. (www.mindgarden.com).
} 
strongly agree). The Cronbach's alpha values for the items measuring individual-focused and group-focused TFL were .92 and .93, respectively. Aggregation indices provided support for our treatment of individual-focused and group-focused TFL as two team-level constructs (individual-focused transformational leadership: mean $\mathrm{rwg}_{(\mathrm{j})}$ uniform $=.94$, mean $\mathrm{rwg}_{(\mathrm{j}) \text { slightly }}$ skewed $=.88 \operatorname{ICC}[1]=.07, \operatorname{ICC}[2]=.23$; group-focused transformational leadership: mean $\operatorname{rwg}_{(\mathrm{j})}$ uniform $=.96 ;$ mean $\operatorname{rwg}_{(\mathrm{j})}$ slightly skewed $\left.=.92 ; \operatorname{ICC}[1]=.17 ; \operatorname{ICC}[2]=.45\right)$.

Control variables. Previous research has suggested that team creativity is likely affected by team members' education (e.g., Carmeli \& Paulus, 2015; Hon \& Chan, 2012) and tenure (e.g., Hu et al., 2018; Shin \& Zhou, 2007; Zhang et al., 2011), which should be controlled for in our data analyses. However, neither team members' average education level $(r=-.16, p=.22)$ nor their average tenure with the organization $(r=.16, p=.21)$ was significantly correlated with team creativity in our data. In addition, neither team members' average education level $(r=.06, p=.62)$ nor their average tenure with the organization $(r$ $=.08, p=.53$ ) was significantly correlated with team members' average individual creativity in our data. Thus, given the small team-level sample size in our data, we followed Bernerth and Aguinis's (2016) recommendations and did not include these factors as control variables to save degree of freedom.

\section{Results}

Preliminary analyses. The means, standard deviations, reliabilities, and correlations are presented in Table 3.

\section{Insert Table 3 about here}

We conducted a set of MCFAs using Mplus 7.4 (Muthén \& Muthén, 2017) to test the discriminant validity among the six latent variables in our model (i.e., employee-rated shared leadership, creative self-efficacy, individual creativity, individual-focused TFL, 
group-focused TFL, and leader-rated team creativity). Following prior research on TFL (e.g., Shin \& Zhou, 2003), we categorized the 12 items measuring individual-focused TFL into two parcels presenting two subdimensions of individualized consideration and intellectual stimulation before running the MCFAs. We also categorized the 12 items measuring group-focused TFL into two parcels representing the two subdimensions of idealized influence and inspirational motivation. Similarly, we categorized the 25 items for shared leadership into four parcels representing four distinct subdimensions (i.e., $P O, P S, S C$, and $D M)$. We opted to use a parceling approach due to our primary interest in the interrelations of our constructs rather than the interrelations of our items within constructs (Little, Rhemtulla, Gibson, \& Schoemann, 2013).

The results showed that our hypothesized six-factor model was a good fit for the data $\left(\chi^{2}=139.80, d f=80, p<.001, \mathrm{CFI}=.97, \mathrm{TLI}=.96, \mathrm{RMSEA}=.06 ; \mathrm{SRMR}_{(\text {within })}=.04\right.$, SRMR (between) $=.00)$. In addition, the decreased fit values and Chi-square difference tests suggested that the six-factor model was superior to the other models. For example, (a) the five-factor model (the correlation of individual-focused TFL and group-focused TFL was set equal to $1 ; \mathrm{CFI}=.94, \mathrm{TLI}=.92, \mathrm{RMSEA}=.07 ; \mathrm{SRMR}($ within $)=.05, \mathrm{SRMR}$ (between) $=.00 ;$ $\left.\Delta \chi^{2} \Delta(2)=119.43, p<.001\right)$, and (b) the four-factor model (the correlation of individual-focused TFL and group-focused TFL was set equal to 1, and the correlation of creative self-efficacy and individual creativity was set equal to $1 ; \mathrm{CFI}=.79, \mathrm{TLI}=.73$, $\left.\operatorname{RMSEA}_{=} .13 ; \operatorname{SRMR}_{(\text {within })}=.11, \operatorname{SRMR}_{(\text {between })}=.00 ; \Delta \chi^{2} \Delta(4)=471.84, p<.001\right)$. Overall, the results of the MCFA supported the discriminant validity of our focal constructs.

Mediation relationships. Given that our data were collected from 18 different firms, we sought to obtain a more robust and conservative test of our hypotheses by accounting for the nested nature of our data (Preacher, Zyphur, \& Zhang, 2010). Specifically, we used Analysis Estimator $=$ MLR and Type $=$ Complex in Mplus (Muthén \& Muthén, 2017). Table 
4 presents the results of our path analysis using Mplus 7.4 (Muthén \& Muthén, 2017). The results from Model 1 show the parameters of path coefficients estimated in a mediation model in which shared leadership predicts team creativity via team members' average creative self-efficacy and average individual creativity on a team. We also estimated the direct influence of shared leadership on team members' average individual creativity and team creativity. In addition, to provide a baseline model for the moderated mediation model that focuses on the moderating role of formal team leaders' individual-focused TFL in the relationship between shared leadership and members' average creative self-efficacy and the moderating role of formal team leaders' group-focused TFL in the relationship between members' average individual creativity and team creativity, we controlled for the influence of individual-focused TFL on members' average creative self-efficacy and the influence of group-focused TFL on team creativity in this mediation model. All predicting variables were grand-mean centered before being entered into the model.

The results revealed that shared leadership was positively related to team members' average creative self-efficacy (estimate $=.29, p=.00$ ), which was further positively related to team members' average individual creativity (estimate $=.35, p=.02)$. Hypothesis $1 \mathrm{~b}$ proposes a team-level, indirect relationship between shared leadership and team members' average individual creativity via collective creative self-efficacy. Because Mplus is unable to generate bootstrapping results for a multilevel model, we utilized the R software (Tofighi \& MacKinnon, 2011) to create Monte Carlo confidence intervals for this indirect relationship (Preacher \& Selig, 2012). The bootstrapping results $(N=20000)$ showed a significant indirect relationship between shared leadership and team members' average individual creativity via collective creative self-efficacy (indirect effect $=.10,95 \% \mathrm{CI}=[.016, .212])$. Thus, Hypothesis 1b was supported. 
Hypothesis 2 proposes a dual-stage, mediating relationship between shared leadership and team creativity via team members' average creative self-efficacy and average individual creativity. The results of Model 1 in Table 4 show a marginally significant, positive relationship between team members' average individual creativity and team creativity (estimate $=.41, p=.06$ ) after controlling for the influences of team members' average creative self-efficacy (estimate $=.23, p=.14)$, shared leadership $($ estimate $=.23, p=.36)$, and formal team leaders' group-focused TFL (estimate $=-.07, p=.80$ ). A bootstrap analysis with 20000 replications revealed that the Monte Carlo-based confidence interval for the indirect relationship between shared leadership and team creativity via team members' average creative self-efficacy and average individual creativity included zero (indirect effect $=.04,95 \%$ $\mathrm{CI}=[-.002, .131])$. Thus, Hypothesis 2 was not supported. This result is consistent with what we found in Study 1, and the insignificant relationship between team members' average individual creativity and team creativity indicates the necessity of taking into account the moderating role of the formally appointed team leader's group-focused TFL.

Moderation effects. On the basis of Model 1 (i.e., the mediation model), we generated a moderated mediation model by creating two interaction terms (i.e., shared leadership $\times$ individual-focused TFL; average individual creativity $\times$ group-focused TFL) and estimated their influences on team members' average creative self-efficacy and team creativity, respectively. Because all variables estimated in the path modeling were manifest variables (i.e., averaged scores of the latent constructs), we followed prior research (e.g., Gong, Wu, Song, \& Zhang, 2017; Hu \& Liden, 2015; Yu \& Zellmer-Bruhn, 2018) and created the interaction term using the products of two manifest variables, which were first centered before being multiplied as the interaction term (Aiken \& West, 1991).

In Model 2 of Table 4, the interaction term of shared leadership with individual-focused TFL was significantly related to team members' average creative 
self-efficacy (estimate $=.69, p=.00$ ). As depicted in Figure 2, simple slopes analysis revealed that shared leadership was positively related to team members' average individual creativity in teams with higher levels of individual-focused TFL (estimate $=.57, p=.00$ ) but less positively related to team members' average creative self-efficacy in teams with lower levels of individual-focused TFL (estimate $=.03, p=.69$ ). The difference between these two simple slopes was significant (estimate $=.53, p=.00$ ). Thus, Hypothesis 3a was supported. Furthermore, Monte Carlo confidence intervals revealed that the indirect relationship between shared leadership and team members' average individual creativity via average creative self-efficacy was more positive when the formally appointed team leader had higher levels of individual-focused TFL (indirect effect $=.20,95 \% \mathrm{CI}=[.040, .385]$ ) than when the formally appointed team leader had lower levels of individual-focused TFL (indirect effect $=.01,95 \% \mathrm{CI}=[-.059, .092])$. The difference between these two indirect effects was also significant (difference $=.18,95 \% \mathrm{CI}=[.032, .370])$. Thus, Hypothesis $3 \mathrm{~b}$ was supported.

Insert Figures 2 and 3 about here

With respect to the moderating role of group-focused TFL, the results showed that the interaction term of team members' average individual creativity with group-focused TFL was significantly related to team creativity (estimate $=.67, p=.03$ ) in this path-analytic model. As depicted in Figure 3, simple slopes analysis revealed that average individual creativity was positively related to team creativity when the formally appointed team leader had higher levels of group-focused TFL (estimate $=.58, p=.00$ ) but was less positively related to team creativity when the formally appointed team leader had lower levels of group-focused TFL (estimate $=.08, p=.78$ ). The difference between these two simple slopes was significant (estimate $=.50, p=.03$ ). Thus, Hypothesis 4a was supported. Furthermore, bootstrap 
analyses further revealed that when group-focused TFL was low, the mediating relationship between shared leadership and team creativity via team members' average creative self-efficacy and average individual creativity was not significant (estimate $=.01,95 \% \mathrm{CI}=$ $[-.046, .070])$. When group-focused TFL was high, however, this dual-stage, mediating relationship was significant $($ estimate $=.06,95 \% \mathrm{CI}=[.004, .156])$. The difference between the two coefficients was also significant (estimate $=.05,95 \% \mathrm{CI}=[.0001, .144])$. These results suggested that shared leadership led to increased team creativity via increased average creative self-efficacy and average individual creativity but only when group-focused TFL was high. Therefore, Hypothesis 4b was supported.

Insert Table 3 about here

Finally, Hypothesis 5 proposes that the dual-stage, mediating relationship between shared leadership and team creativity via team members' average creative self-efficacy and average individual creativity will be most positive when the formally appointed team leader has both high levels of individual-focused TFL and high levels of group-focused TFL. Table 3 presents the Monte Carlo confidence intervals for this dual-stage, mediating relationship at different levels of individual- and group-focused TFL. The results suggested that this indirect effect was significantly positive under the condition of high individual-focused TFL and high group-focused TFL (indirect effect $=.11,95 \% \mathrm{CI}=[.007, .285])$ and the condition of average individual-focused TFL and high group-focused TFL (indirect effect $=.06,95 \% \mathrm{CI}=$ $[.004, .156])$. Moreover, the indirect effect under the condition of high individual-focused TFL and high group-focused TFL was significantly larger than (a) the indirect effect under the condition of low individual-focused TFL and high group-focused TFL (indirect effect $=.01,95 \% \mathrm{CI}=[-.039, .061]):$ difference $=.11,95 \% \mathrm{CI}=[.007, .274],(\mathrm{b})$ the indirect effect 
under the condition of high individual-focused TFL and low group-focused TFL (indirect effect $=.02,95 \% \mathrm{CI}=[-.086, .128]):$ difference $=.10,95 \% \mathrm{CI}=[.001, .257]$, and (c) the indirect effect under the condition of low individual-focused TFL and low group-focused TFL (indirect effect $=.00,95 \% \mathrm{CI}=[-.017, .022])$ : difference $=.11,95 \% \mathrm{CI}=[.007, .280]$. These results together provided support for our Hypothesis 5.

\section{General Discussion}

Drawing on the componential model of creativity (Amabile, 1988), we developed and tested a dual-stage model examining how shared leadership increases team creativity. Empirical results from two studies employing both experimental and multisource time-lagged survey designs provided support for the influences of shared leadership on team members' creative self-efficacy and, in turn, individual creativity, which further contributes to team creativity. Moreover, formal team leaders' individual-focused and group-focused TFL behaviors were found to strengthen this process in different ways - individual-focused TFL facilitates shared leadership's positive influences on team members' creative self-efficacy and in turn individual creativity, whereas group-focused TFL plays a vital role in translating team members' individual creativity into overall team creativity.

\section{Theoretical Contributions}

Several theoretical contributions are worth highlighting. First, we advance the current understanding of the role of various forms of leadership in producing team creativity by demonstrating the positive influence of shared leadership in addition to the influence of vertical leadership (e.g., formal team leaders' transformational behaviors). Both shared leadership and formally appointed leaders' vertical leadership exert a unique impact on a team's creative processes. Shared leadership enhances the individual creativity of team members and of the team as a whole, but this bottom-up influence on team creativity originates from shared leadership and is maximized by the formally appointed leader's usage 
of transformational behaviors. The finding about the significance of shared leadership could redirect at least some of the scholarly attention from focusing on formal team leaders' individual traits, behaviors, and styles that are beneficial to the development of team creativity (i.e., vertical leadership influence) to focusing on team members' lateral and mutual influence processes that can also generate a positive, upward influence on team creativity.

Moreover, our finding that the indirect relationship between shared leadership and team creativity via team members' average creative self-efficacy and average individual creativity is enhanced by formal leaders' transformational behaviors deepens our understanding regarding the boundary conditions of the effectiveness of shared leadership (Wang et al., 2014). This finding also underscores the importance of examining the coexistence of different sources of leadership within a team (e.g., Morgeson et al., 2010; Yammarino et al., 2012). Specifically, our results suggest that shared leadership and vertical leadership benefit the team creative process in different ways — shared leadership benefits team creativity by cultivating more creative individuals on a team, whereas the formally appointed team leader benefits team creativity by not only strengthening the process of cultivating creative individuals through shared leadership (via individual-focused TFL behaviors) but also affecting the process of translating creative individuals into creative teams (via group-focused TFL behaviors). This joint influence of shared leadership and the formally appointed leader's vertical leadership (TFL) on team creativity has two specific implications for our proposed bottom-up, dual-stage team creative process.

First, regarding the stage of cultivating creative team members, our findings extend the current shared leadership research by identifying individual creativity as an important yet overlooked individual outcome of shared leadership. Despite the progress made in understanding the beneficial team outcomes of shared leadership (Wang et al., 2014), researchers have only recently begun to focus on the effects of shared leadership on 
individual psychological and behavioral outcomes. For example, Liu et al. (2014) demonstrated that individual learning behavior is one positive individual-level outcome of shared leadership. Although learning behavior is a vital precursor to individual creativity (Hirst, van Knippenberg, \& Zhou, 2009), we extend Liu and colleagues' (2014) work by providing direct empirical evidence for the positive influence of shared leadership on individual creativity. More importantly, our findings provide insights into why shared leadership motivates individual behaviors by revealing "can-do" motivation (e.g., creative self-efficacy) as one possible intervening mechanism. Furthermore, our findings suggest that shared leadership and vertical leadership have synergetic influences on team members' individual creativity — the positive influences of team members' lateral social interactions on individual creative self-efficacy and outcomes are enhanced by the formal leader's downward performance of individualized consideration and intellectual stimulation that can provide members with a legitimate authority and encouragement to engage in risky, creative endeavors at work.

Second, for the stage of translating team members' individual creativity into team creativity, the empirical results underscore the vital role of vertical leadership. In other words, our findings suggest that shared leadership cannot promote team creativity without the presence of the formally appointed team leader's group-focused TFL behaviors because of the nonsignificant relationship between team members' average individual creativity and team creativity. These results provide empirical evidence for the theoretical argument that the synthesis of individual creative acts into team creativity depends on context (Harvey, 2014), particularly the context provided by a formally appointed leader who clarifies the collective mission and energizes and inspires efforts toward the achievement of goals that ultimately matter for these teams - creative products that individuals alone are not able to produce. 
Finally, our research contributes to the componential model of creativity by providing a contextualized and nuanced understanding of multiple creative episodes occurring at different levels (i.e., individual and team). Specifically, the original componential model of creativity (Amabile, 1988) posits that individual creative processes can be extended to the creative processes of small groups or teams. Consistent with this argument and prior research findings (Pirola-Merlo \& Mann, 2004; Taggar, 2002), our results suggest that team members' individual attributes (e.g., knowledge, expertise, and information) and behaviors (e.g., creative actions) can provide diversified resources that are vital for the generation of team creativity. However, recent research has underscored the uniqueness of team creative processes by emphasizing the influences of positive team processes that can facilitate resource integration and synthesis (Hargadon \& Bechky, 2006; Harvey, 2014). Accordingly, Amabile and Pratt (2016) have revised the componential model of creativity by explicitly recognizing the difference between the individual creative process and the team creative process. In particular, the revised model emphasizes the cyclical and ongoing nature of creative processes existing across different levels inside an organization and elaborates how contextual factors such as leadership may shape these dynamic, creative processes occurring at different levels. Although our research cannot directly demonstrate this dynamic process, the moderating role of formal leaders' group-focused TFL in the relationship between team members' average individual creativity and team creativity as demonstrated in Study 2 provides indirect support for the contextual influence of vertical leadership on synthesizing creative processes across different levels inside an organization.

\section{Practical Implications}

Our findings underscore the importance of cultivating shared leadership in teams and encouraging formal team leaders' transformational behaviors to foster team creativity in 
organizations. Thus, we offer several practical implications for both organizations and managers who expect the achievement of high team creativity.

Organizations would be well served to do what they can to support team members sharing different aspects of leadership roles. Enhancing shared leadership might be accomplished in a number of ways. First, in situations in which it is feasible, organizations might consider employing a multiteam system in which multiple homogenous, self-managed teams, such as the R\&D teams in Study 2, are nested in a large group or center and are led by a formal leader. Second, organizations can foster shared leadership in teams by establishing a supportive and autonomous climate that encourages self-leadership (Carson et al., 2007). Third, because creative individuals were found to be the driving force of team creativity in our research, organizations should develop a supportive environment for individual creative engagement activities, such as providing sufficient resources (e.g., facilities, equipment, funds) for creativity and employing a developmental reward system that can protect employees' intrinsic motivation and tolerate their failures in creative explorations (Amabile, 1988). Rewarding employees who voice creative ideas and solutions for work-related issues can be another useful practice. Finally, organizations can improve the average level of individual creativity of a team through the HR management practices of recruitment and training programs.

For team managers, one straightforward suggestion is to empower employees to create a participative and delegated team climate in order to achieve higher degrees of shared leadership (Margolis \& Ziegert, 2016). Moreover, managers should display different vertical leadership behaviors at different stages in the team creative process. When the goal is to foster team members' individual creativity, managers are encouraged to share power with team members to cultivate shared leadership. Meanwhile, they are encouraged to perform individual-focused transformational behaviors associated with individualized consideration, 
such as being responsive to team members' job-related needs, and intellectual stimulation, such as encouraging team members to see a job-related problem through different angles and perspectives. When the team has many creative team members but not a high level of team creativity, managers should intentionally display group-focused transformational behaviors of idealized influence and inspirational motivation. Specifically, managers can make team members feel proud to be associated with the team through social-emotional influences that underscore the team's collective mission and values.

\section{Limitations and Future Directions}

The current research has several limitations, highlighting important directions for future research. First, it is important to note that there are a number of alternative mechanisms that may account for the influences of shared leadership on team creativity that we could not rule out in our empirical findings. For instance, we did not consider team processes as parallel mediators in the relationship between shared leadership and team creativity. Thus, we could not conclude that team members' individual creativity or the average individual creativity on a team serve as unique mechanisms explaining the downward influence of shared leadership on team creativity. It is also possible that team members' mutual and reciprocal influence processes as manifested by shared leadership cultivate positive team processes, such as stronger shared goals and mission, and more frequent information exchange and knowledge sharing, leading to the subsequent generation of team creativity (c.f., Wang et al., 2014). This issue may be particularly salient in our field study because the measures of shared leadership we used from Hiller et al. (2006) include four leadership functions that can also be employed to capture the process of members' mutual influences throughout different stages (i.e., transition, action, and interpersonal) of the team process (Marks, Mathieu, \& Zaccaro, 2001). Despite the emphasis on leaders' roles/functions in our measures (see the Appendix), we urge future research to simultaneously examine 
creative individuals and team processes as two parallel mediating mechanisms in the relationship between shared leadership and team creativity and to investigate the boundary conditions to further unravel when one mechanism overrides the other.

In addition, although we collected our field data from different sources at different time points, shared leadership and creative self-efficacy were still measured from the same source (i.e., team members) and at the same time (T1). Thus, based on the empirical findings of our field study, we cannot make any causal inference between shared leadership and team members' average creative self-efficacy. In other words, because prior research has suggested that individuals' various skills and capabilities are precursors of individual leader emergence (Carson et al., 2007; Zhang, Waldman, \& Wang, 2012), it is possible that teams with members who have higher levels of creative self-efficacy are more conducive to the formation of shared leadership. Due to this causality issue, we feel that our experiment (Study 1) plays a vital role in not only revealing the individual-level relationship between shared leadership and individual creativity via individual creative self-efficacy, which provides the microfoundation for the team-level relationships proposed in our model, but also establishing the causal directions between shared leadership and individual creative self-efficacy and between shared leadership and team members' average creative self-efficacy. Nonetheless, future studies collecting longitudinal data to directly capture the dynamic process of how changes in shared leadership relate to changes in team members' individual creativity and team creativity will be preferred because these studies can replicate and extend our empirical findings in an empirically more robust way, and they can test the multilevel relationships proposed in the updated, dynamic componential model of creativity (Amabile \& Pratt, 2016).

Moreover, due to the small team-level sample sizes in both studies, we only ran path-analyses instead of SEM in testing our proposed team-level relationships. Even though our CFAs showed satisfactory fitness of our data with the measurement models, we 
encourage future studies to replicate our team-level empirical findings by simultaneously estimating the measurement model and interrelationships among the focal latent constructs in a SEM which requires data from a larger sample size. Another concern related to the sample issue is the non-response bias that possibly existed in Study 2. We know that the average response rate for team-members across all 69 teams at Time 1 was $90.8 \%$. Unfortunately, we did not collect data on team size and thus we were unable to calculate the range of within-team response rates for our sampled teams. While we are unable to rule out the possibility that the $9 \%$ of non-responders were disproportionately from a subset of teams (making the response rates within those teams low), we have no reason to believe that they were from only a small subset of teams. Based on our formal and informal conversations with individuals, leaders, and HR managers from the organizations that occurred during and around the time of our survey administrations, we were told to expect some non-response due to illness, travel, and other reasons_-reasons that would not be typically associated with systemic problems of response bias.

Finally, given the relatively similar nature of team goals among our sample teams in both studies (i.e., business plan competition teams who focused largely on creativity in Study 1 and R\&D teams in Study 2), we suggest caution in generalizing our findings to work groups whose main goals are something other than creative outputs. For instance, our finding that creative self-efficacy mediated the effect of shared leadership on both individual creativity and team creativity may be due in part to the creative nature of the team goals of our sample teams - individuals are more likely to gain confidence to engage in creative explorations (i.e., creative self-efficacy) when they are required to find and are rewarded for finding creative solutions at work than when they are required to perform and are rewarded for performing routine tasks. We thus encourage future researchers to investigate more work teams with different work attributes to generalize and extend our research findings. 


\section{Conclusion}

In this paper, we provided evidence that shared leadership has a direct effect on the individual motivational state of creative self-efficacy, which in turn increases individual creativity and team creativity. We also demonstrated that formal team leaders' individual-focused and group-focused transformational behaviors play important yet different roles in facilitating this team-level relationship between shared leadership and team creativity via team members' average creative self-efficacy and average individual creativity. 


\section{References}

Aiken, L. S., \& West, S. G. (1991). Multiple regression: Testing and interpreting interactions. Newbury Park, CA: Sage.

Amabile, T. M. (1988). A model of creativity and innovation in organizations. In B. M. Staw \& L. L. Cummings (Eds.), Research in organizational behavior, 10, 123-167. Greenwich, CT: JAI Press.

Amabile, T. M., \& Pratt, M. G. (2016). The dynamic componential model of creativity and innovation in organizations: Making progress, making meaning. Research in Organizational Behavior, 36, 157-183. doi: 10.1016/j.riob.2016.10.001

Anderson, N., Potočnik, K., \& Zhou, J. (2014). Innovation and creativity in organizations: A state-of-the-science review, prospective commentary, and guiding framework. Journal of Management, 40, 1297-1333. doi:10.1177/0149206314527128

Aragón-Correa, J. A., García-Morales, V. J., \& Cordón-Pozo, E. (2007). Leadership and organizational learning's role on innovation and performance: Lessons from Spain. Industrial Marketing Management, 36, 349-359. https://doi.org/10.1016/j.indmarman.2005.09.006

Avolio, B. J., \& Gibbons, T. C. (1988). Developing transformational leaders: A life span approach. In J. A. Conger \& R. N. Kanungo, The Jossey-Bass management series. Charismatic leadership: The elusive factor in organizational effectiveness (pp. 276308). San Francisco, CA, US: Jossey-Bass.

Avolio, B. J., Jung, D., Murray, W., \& Sivasubramaniam, N. (1996). Building highly developed teams: Focusing on shared leadership process, efficacy, trust, and performance. In M. M. Beyerlein, D. A. Johnson, \& S. T. Beyerlein (Eds.), Advances in interdisciplinary studies of work teams (pp. 173-209). Greenwich, CT: JAI Press.

Baer, M., \& Oldham, G. R. (2006). The curvilinear relation between experienced creative time pressure and creativity: Moderating effects of openness to experience and 
support for creativity. Journal of Applied Psychology, 91, 963-970. doi:

$10.1037 / 0021-9010.91 .4 .963$

Bandura, A. (1997). Self-efficacy: The exercise of control. New York, NY: W.H. Freeman.

Bandura, A. (1986). Social foundations of thought and action: A social-cognitive view. Englewood Cliffs, NJ: Prentice-Hall.

Barling, J., Webber, T., \& Kelloway, E. K. (1996). Effects of transformational leadership tranining on attitudinal and financial outcomes: A field experiment. Journal of Applied Psychology, 81, 827-832.

Bass, B. M. (2008). The Bass handbook of leadership: Theory, research, \& managerial applications (4th ed.). New York, NY: Free Press. Press.

Bass, B. M., \& Avolio, B. J. (1995). MLQ multifactor leadership questionnaire (2nd Ed.). Redwood City, CA: Mind Garden.

Bernerth, J. B., \& Aguinis, H. (2016). A critical review and best-practice recommendations for control variable usage. Personnel Psychology, 69, 229-283. https://doi.org/10.1111/peps.12103

Bliese, P. D. (2000). Within-group agreement, non-independence, and reliability: Implications for data aggregation and analysis. In K. J. Klein and S. W. J. Kozlowski (Eds.), Multilevel Theory, Research, and Methods in Organizations (pp. 349-381). San Francisco, CA: Jossey-Bass.

Boies, K., Lvina, E., \& Martens, M. L. (2010). Shared leadership and team performance in a business strategy simulation. Journal of Personal Psychology, 9, 195-202. doi: $10.1027 / 1866-5888 / \mathrm{a} 000021$

Brislin, R. W. (1986). The wording and translation of research instruments. In W. J. Lonner \& J. W. Berry (Eds.), Field methods in cross-cultural research (pp. 137-164). Beverly Hills, CA: Sage. 
Carmeli, A., \& Paulus, P. B. (2015). CEO ideational facilitation leadership and team creativity: The mediating role of knowledge sharing. Journal of Creative Behavior, 49, 53-75. https://doi.org/10.1002/jocb.59

Carson, J. B., Tesluk, P. E., \& Marrone, J. A. (2007). Shared leadership in teams: An investigation of antecedent conditions and performance. Academy of Management Journal, 50, 1217-1234. doi: 10.2307/AMJ.2007.20159921

Chen, G., Farh, J. L., Campbell-Bush, E. M., Wu, Z., \& Wu, X. (2013). Team as innovative systems: Multilevel motivational antecedents of innovation in R\&D teams. Journal of Applied Psychology, 98, 1018-1027. doi: 10.1037/a0032663

Chen, G., Sharma, P. N., Edinger, S. K., Shapiro, D. L. and Farh, J. L. (2011). Motivation and demotivating forces in teams: Cross-level influence of empowering leadership and relationship conflict. Journal of Applied Psychology, 96, 541-557. http://dx.doi.org/10.1037/a0021886

Chiu, C. C., Owens, B. P., \& Tesluk, P. E. (2016). Initiating and utilizing shared leadership in teams: The role of leader humility, team proactive personality, and team performance capability. Journal of Applied Psychology, 101, 1705-1720. doi: 10.1037/ap10000159

Chun, J. U.., Cho, K., \& Sosik, J. J. (2016). A multilevel study of group-focused and individual-focused transformational leadership, social exchange relationships, and performance in teams. Journal of Organizational Behavior, 37, 374-396. doi: 10.1002/job.2048

Contractor, N. S., DeChurch, L. A., Carson, J., Carter, D. R., \& Keegan, B. (2012). The topology of collective leadership. The Leadership Quarterly, 23, 994-1011. doi: 10.1016/j.leaqua.2012.10.010

D'Aveni, R. A. (2010). Hypercompetition. Simon and Schuster.

Davis, J. P., \& Eisenhardt, K. M. (2011). Rotating leadership and collaborative innovation. Administrative Science Quarterly, 56, 159-201. https://doi.org/10.1177/0001839211428131 
D’Innocenzo, L., Mathieu, J. E., \& Kukenberger, M. R. (2016). A meta-analysis of different forms of shared leadership-team performance relations. Journal of Management, 42, 1964-1991. doi: 10.1177/0149206314525205

Ensley, M. D., Hmieleski, K. M., \& Pearce, C. L. (2006). The importance of vertical and shared leadership within new venture top management teams: Implications for the performance of startups. The Leadership Quarterly, 17, 217-231. doi: 10.1016/j.leaqua.2006.02.002

Erez, A., Lepine, J. A., \& Elms, H. (2002). Effects of rotated leadership and peer evaluation on the functioning and effectiveness of self-managed teams: a quasi-experiment. Personnel Psychology, 55, 929-948. https://doi.org/10.1111/j.1744-6570.2002.tb00135.x

Erkutlu, H. (2012). The impact of organizational culture on the relationship between shared leadership and team proactivity. Team Performance Management, 18, 102-119. doi: $10.1108 / 13527591211207734$

Farh, J. L., Lee, C., \& Farh, C. I. C. (2010). Task conflict and team creativity: A question of how much and when. Journal of Applied Psychology, 95, 1173-1180. doi: $10.1037 / \mathrm{a} 0020015$

Ford, C. M. (1996). A theory of individual creative action in multiple social domains. Academy of Management review, 21, 1112-1142. doi:10.5465/AMR.1996.9704071865

Gilson, L. L., \& Shalley, C. E. (2004). A little creativity goes a long way: An examination of teams' engagement in creative processes. Journal of Management, 30, 453-470. doi:10.1016/j.jm.2003.07.001

Gilson, L. L., Litchfield, R., Lim, H. S., \& Gilson, P. W. (2015). Creativity in teams: Directions for future research. In C. E. Shalley, M. A. Hitt, \& J. Zhou (Eds.), The Oxford Handbook of Creativity, Innovation, and Entrepreneurship (pp. 177-205). Oxford University Press, New York. 
Girotra, K., Terwiesch, C., \& Ulrich, K. T. (2010). Idea generation and the quality of the best idea. Management Science, 56, 591-605. doi: 10.1287/mnsc.1090.1144

Gong, Y., Huang, J. C., \& Farh, J. L. (2009). Employee learning orientation, transformational leadership, and employee creativity: The mediating role of employee creative self-efficacy. Academy of Management Journal, 52, 765-778. doi:

10.5465/AMJ.2009.43670890

Gong, Y., Wu, J., Song, L. J., \& Zhang, Z. (2017). Dual tuning in creative processes: Joint contributions of intrinsic and extrinsic motivational orientations. Journal of Applied Psychology, 102, 829-844. doi: 10.1037/ap10000185

Gong, Y., Kim, T. Y., Lee, D. R., \& Zhu, J. (2013). A multilevel model of team goal orientation, information exchange, and creativity. Academy of Management Journal, 56, 827-851. doi: 10.5465/amj.2011.0177

Hargadon, A. B., \& Bechky, B. A. (2006). When collections of creative become creative collectives: A field study of problem solving at work. Organization Science, 17, 484500. https://doi.org/10.1287/orsc.1060.0200

Harvey, S. (2014). Creative synthesis: Exploring the process of extraordinary group creativity. Academy of Management Review, 39, 324-343. doi:10.5465/amr.2012.0224

Hiller, N. J., Day, D. V., \& Vance, R. J. (2006). Collective enactment of leadership roles and team effectiveness: A field study. The Leadership Quarterly, 17, 387-397. doi: 10.1016/j.leaqua.2006.04.004

Hirst, G., van Knippenberg, D., \& Zhou, J. (2009). A cross-level perspective on employee creativity: Goal orientation, team learning behavior, and individual creativity. Academy of Management Journal, 52, 280-293. doi: 10.5465/AMJ.2009.37308035

Hoch, J. E. (2013). Shared leadership and innovation: The role of vertical leadership and employee integrity. Journal of Business and Psychology, 28, 159-174. doi: 10.1007/s10869-012-9273-6 
Hooker, C., \& Csikszentmihalyi, M. (2003). Flow, creativity, and shared leadership:

Rethinking the motivation and structuring of knowledge work. In C. L. Pearce \& J. A. Conger (Eds.), Shared leadership: Reframing the hows and whys of leadership (pp. 217-234). Thousand Oaks, CA: Sage.

Hon, A. H., \& Chan, W. W. (2012). Team creative performance: The role of empowering leadership, creative-related motivation, and task interdependence. Cornell Hospitality Quarterly, 54, 199-210. doi: 10.1177/1938965512455859

Hu, J., Ergon, B., Jiang, K., Bauer, T. N., Liu, S. (2018). Leader humility and team creativity: The role of team information sharing, psychological safety, and power distance. Journal of Applied Psychology, 103: 313-323. http://dx.doi.org/10.1037/ap10000277

Hu, J., \& Liden, R. C. (2015). Making a difference in the teamwork: Linking team prosocial motivation to team processes and effectiveness. Academy of Management Journal, 58, 1102-1127. doi: 10.5465/amj.2012.1142

Kark, R., \& Shamir, B. 2002. The dual effect of transformational leadership: Priming relational and collective selves and further effects on followers. In B. J. Avolio \& F. J. Yammarino (Eds.), Transformational and charismatic leadership: The road ahead, vol. 2: 67-91. Amsterdam: JA1 Press.

Little, T. D., Rhemtulla, M., Gibson, K., \& Schoemann, A. M. (2013). Why the items versus parcels controversy needn't be one. Psychological Methods, 18, 285-300. doi: $10.1037 / \mathrm{a} 0033266$

Liu, S., Hu, J., Li, Y., Wang, Z., \& Lin, X. (2014). Examining the cross-level relationship between shared leadership and learning in teams: Evidence from China. The Leadership Quarterly, 25, 282-295. doi: 10.1016/j.leaqua.2013.08.006

Margolis, J. A., \& Ziegert, J. C. (2016). Vertical flow of collectivistic leadership: an examination of the cascade of visionary leadership across levels. Leadership Quarterly, 27, 334-348. https://doi.org/10.1016/j.leaqua.2016.01.005 
Marks, M. A., Mathieu, J. E., \& Zaccaro, S. J. (2001). A temporally based framework and taxonomy of team processes. Academy of Management Review, 26, 356-376. doi: $10.2307 / 259182$

Mayo, M., Meindl, J. R., \& Pastor, J. C. (2003). Shared leadership in work teams: A social network approach. In C. L. Pearce \& J. A. Conger (Eds.), Shared leadership: Reframing the hows and whys of leadership (pp.193-214). Thousand Oaks, CA: Sage.

McAllister, D. J., Kamdar, D., Morrison, E. F., \& Turban, D. B. 2007. Disentangling role perceptions: How perceived role breadth, discretion, instrumentality, and efficacy relate to helping and taking charge. Journal of Applied Psychology, 92, 1200-1211. doi: 10.1037/0021-9010.92.5.1200

Morgeson, F. P., \& DeRue, D. S., \& Karam, E. P. (2010). Leadership in teams: A functional approach to understanding leadership structures and processes. Journal of Management, 36, 5-39. doi: 10.1177/0149206309347376

Muthén, L.K. and Muthén, B.O. (2017). Mplus User's Guide. Eight Edition. Los Angeles, CA: Muthén \& Muthén.

Nicolaides, V. C., LaPort, K. A., Chen, T. R., Tomassetti, A. J., Weis, E. J., Zaccaro, S. J., \& Cortina, J. M. (2014). The shared leadership of teams: A meta-analysis of proximal, distal, and moderating relationships. The Leadership Quarterly, 25, 923-942. http://dx.doi.org/10.1016/j.leaqua.2014.06.006

Pearce, C. L., \& Conger, J. A. (2003). All those years ago: The historical underpinnings of shared leadership. In C. L. Pearce \& J. A. Conger (Eds.), Shared leadership: Reframing the hows and whys of leadership (pp. 1-18). Thousand Oaks, CA: Sage. doi:10.4135/9781452229539.n1

Pearce, C. L., \& Sims, H. P. (2002). Vertical versus shared leadership as predictors of the effectiveness of change management teams: An examination of aversive, directive, transactional, transformational, and empowering leader behaviors. Group dynamics: Theory, research, and practice, 6, 172-197. doi: 10.1037//1089-2699.6.2.172 
Pearce, C. L., Yoo, Y., \& Alavi, M. (2004). Leadership, social work and virtual teams: The relative influence of vertical vs. shared leadership in the nonprofit sector. In R. E. Riggio \& S. Smith-Orr (Eds.), Improving leadership in nonprofit organizations (pp. 180-203). San Francisco: Jossey-Bass.

Pirola-Merlo, A., \& Mann, L. (2004). The relationship between individual creativity and team creativity: Aggregating across people and time. Journal of Organizational Behavior, 25, 235-257. doi: 10.1002/job.240

Preacher, K. J., Zyphur, M. J., \& Zhang, Z. (2010). A general multilevel SEM framework for assessing multilevel mediation. Psychological Methods, 15, 209233.10.1037/a0020141

Preacher, K. J., Selig, J. P. (2012). Advantages of Monte Carlo confidence intervals for indirect effects. Communication Methods and Measures, 6, 77-98. $10.1080 / 19312458.2012 .679848$

Shalley, C. E. (1991). Effects of productivity goals, creativity goals, and personal discretion on individual creativity. Journal of Applied psychology, 76, 179-185. doi: $10.1037 / 0021-9010.76 .2 .179$

Shalley, C. E., \& Perry-Smith, J. E. (2008). The emergence of team creative cognition: The role of diverse outside ties, sociocognitive network centrality, and team evolution. Strategic Entrepreneurship Journal, 2, 23-41. doi: 10.1002/sej.40

Shin, S. J., \& Zhou, J. (2003). Transformational leadership: Conservation, and creativity: Evidence from Korea. Academy of Management Journal, 46, 703-714. doi: $10.2307 / 30040662$

Shin, S. J., \& Zhou, J. (2007). When is educational specialization heterogeneity related to creativity in research and development teams? Transformational leadership as a moderator. Journal of Applied Psychology, 92, 1709-1721. doi:

10.1037/0021-9010.92.6.1709 
Taggar, S. (2002). Individual creativity and group ability to utilize individual creative resources: A multilevel model. Academy of Management Journal, 45, 315-330. doi: $10.2307 / 3069349$

Tierney, P., \& Farmer, S. M. (2002). Creative self-efficacy: The potential antecedents and relationship to creative performance. Academy of Management Journal, 45, 11371148. doi: $10.2307 / 3069429$

Tierney, P., \& Farmer, S. M. (2011). Creative self-efficacy development and creative performance over time. Journal of Applied Psychology, 96, 277-293. doi: $10.1037 / \mathrm{a} 0020952$

Tofighi, D., \& MacKinnon, D. P. (2011). RMediation: An R package for mediation analysis confidence intervals. Behavior Research Methods, 43, 692-700. doi: $10.3758 / \mathrm{s} 13428-011-0076-\mathrm{X}$

van Knippenberg, D., \& Sitkin, S. B. (2013). A critical assessment of charismatictransformational leadership research: Back to the drawing board? Academy of Management Annals, 7, 1-60. doi: 10.1080/19416520.2013.759433

Wang, D., Waldman, D. A., \& Zhang, Z. (2014). A meta-analysis of shared leadership and team effectiveness. Journal of Applied Psychology, 99, 181-198. doi: $10.1037 / \mathrm{a} 0034531$

Wang, X. H., \& Howell, J. M. (2010). Exploring the dual-level effects of transformational leadership on followers. Journal of Applied Psychology, 95, 1134-1144. doi: $10.1037 / \mathrm{a} 0020754$

Wood, M. S. (2005). Determinants of shared leadership in management teams. International Journal of Leadership Studies, 1, 64-85.

Wood, M. S., \& Fields, D. (2007). Exploring the impact of shared leadership on management team member job outcomes. Baltic Journal of Management, 2, 251-272. doi: $10.1108 / 17465260710817474$ 
Woodman, R. W., Sawyer, J. E., \& Griffin, R. W. (1993). Toward a theory of organizational creativity. Academy of Management Review, 18, 293-321. doi: 10.5465/AMR.1993.3997517

Wu, J. B., Tsui, A. S., \& Kinicki, A. J. (2010). Consequences of differentiated leadership in groups. Academy of Management Journal, 53, 90-106. doi: 10.5465/AMJ.2010.48037079

Yammarino, F. J., Salas, E., Serban, A., Shirreffs, K., \& Shuffler, M. L. (2012). Collectivistic leadership approaches: Putting the "we" in leadership science and practice. Industrial and Organizational Psychology: Perspectives on Science and Practice, 5, 382-402. doi: 10.1111/j.1754-9434.2012.01467.x

Yu, L., \& Zellmer-Bruhn, M. Introducing team mindfulness and considering its safeguard role against conflict transformation and social undermining. Academy of Management Journal, 61, 324-347. doi: 10.5465/amj.2016.0094

Zhang, X., \& Bartol, K. M. (2010). Linking empowering leadership and employee creativity: The influence of psychological empowerment, intrinsic motivation, and creative process engagement. Academy of Management Journal, 53, 107-128. http://dx.doi.org/10.5465/AMJ.2010.48037118

Zhang, A. Y., Tsui, A. S., Wang, D. X. (2011). Leadership behaviors and group creativity in Chinese organizations: The role of group processes. The Leadership Quarterly, 22, 851-862. doi: 10.1016/j.leaqua.2011.07.007

Zhang, Z., Waldman, D. A., \& Wang, Z. (2012). A multilevel investigation of leader-member exchange, informal leader emergence, and individual and team performance. Personnel Psychology, 65, 49-78. doi: 10.1111/j.1744-6570.2011.01238.x

Zhou, J., \& George, J. M. (2001). When job dissatisfaction leads to creativity: Encouraging the expression of voice. Academy of Management Journal, 44, 682-696. doi: $10.2307 / 3069410$ 
Zhou, J., \& Oldham, G. R. (2001). Enhancing creative performance: Effects of expected developmental assessment strategies and creative personality. The Journal of Creative Behavior, 35, 151-167. DOI: 10.1002/j.2162-6057.2001.tb01044.x 


\section{SHARED LEADERSHIP AND TEAM CREATIVITY 56}

Table 1

Descriptive Statics and Correlations among the Variables in Study 1

\begin{tabular}{lccccc}
\hline \multicolumn{1}{c}{ Variables } & $M$ & $S D$ & \multicolumn{3}{c}{ Correlations } \\
& & & 1 & 2 & 3 \\
\hline Individual-level variables $(N=109)$ & & & & & \\
$\quad$ 1. Shared leadership & .49 & .50 & - & & \\
2. Creative self-efficacy & 3.78 & .65 & $.23^{*}$ & - & \\
3. Individual creativity & 4.14 & .55 & $.28^{* *}$ & $.50^{* *}$ & - \\
Team-level variables $(N=32)$ & & & & & \\
1. Shared leadership & .50 & .51 & - & & \\
2. Average creative self-efficacy & 3.78 & .37 & $.35^{*}$ & - & \\
3. Average individual creativity & 4.15 & .37 & $.35^{*}$ & $.66^{* *}$ & - \\
4. Team creativity & 4.13 & .91 & $.53^{* *}$ & $.40^{*}$ & $.38^{*}$ \\
\hline
\end{tabular}

Note: $* p \leq .05 . * * p \leq .01$. 
Table 2

Unstandardized Coefficients of the Path Analysis in Study 1

\begin{tabular}{|c|c|c|c|c|c|c|c|c|c|c|c|c|c|c|c|}
\hline \multirow[b]{4}{*}{ Model 1: Individual-level analvsis } & \multicolumn{6}{|c|}{$\begin{array}{c}\text { Model } 1 \\
\text { (Individual-level analysis) }\end{array}$} & \multicolumn{9}{|c|}{$\begin{array}{c}\text { Model 2 } \\
\text { (Team-level analysis) }\end{array}$} \\
\hline & \multicolumn{3}{|c|}{$\begin{array}{l}\text { Individual Creative } \\
\text { Self-Efficacy }\end{array}$} & \multicolumn{3}{|c|}{ Individual Creativity } & \multicolumn{3}{|c|}{$\begin{array}{l}\text { Average Creative } \\
\text { Self-Efficacy }\end{array}$} & \multicolumn{3}{|c|}{$\begin{array}{l}\text { Average Individual } \\
\text { Creativity }\end{array}$} & \multicolumn{3}{|c|}{ Team Creativity } \\
\hline & Estimate & $S E$ & $p$ & Estimate & $S E$ & $p$ & Estimate & $S E$ & $p$ & Estimate & $S E$ & $p$ & Estimate & $S E$ & $p$ \\
\hline & & & & & & & & & & & & & & & \\
\hline Intercept & $3.64 * * *$ & .08 & .00 & $2.60 * * *$ & .28 & .00 & & & & & & & & & \\
\hline Shared leadership & $.30 *$ & .12 & .01 & $.19^{*}$ & .09 & .03 & & & & & & & & & \\
\hline Individual creative self-efficacy & & & & $.38 * * *$ & & .00 & & & & & & & & & \\
\hline$R^{2}$ & & 05 & & .2 & 28 & & & & & & & & & & \\
\hline \multicolumn{16}{|l|}{ Model 2: Team-level analysis } \\
\hline Intercept & & & & & & & $3.65 * * *$ & .09 & .00 & $1.80 * *$ & .57 & .00 & 1.03 & 1.66 & .53 \\
\hline Shared leadership & & & & & & & $.26^{*}$ & .12 & .04 & .10 & .11 & .35 & $.76^{*}$ & .31 & .01 \\
\hline Average creative self-efficacy & & & & & & & & & & $.61 * * *$ & .15 & .00 & .42 & .49 & .39 \\
\hline Average individual creativity & & & & & & & & & & & & & .27 & .50 & .59 \\
\hline$R^{2}$ & & & & & & & .1 & 2 & & & 33 & & & .46 & \\
\hline
\end{tabular}

$$
\text { Note: } * p<.05 . * * p<.01 . * * * p<.001 \text {. }
$$


Table 3

Descriptive Statics and Correlations among the Variables in Study 2

\begin{tabular}{|c|c|c|c|c|c|c|c|c|}
\hline \multirow{2}{*}{ Variables } & \multirow{2}{*}{$M$} & \multirow{2}{*}{$S D$} & \multicolumn{6}{|c|}{ Correlations } \\
\hline & & & 1 & 2 & 3 & 4 & 5 & 6 \\
\hline 1. Shared leadership & 5.20 & .52 & - & & & & & \\
\hline 2. Average creative self-efficacy & 3.48 & .37 & $.41 * *$ & - & & & & \\
\hline 3. Average individual creativity & 3.49 & .53 & $.36^{* *}$ & $.35 * *$ & - & & & \\
\hline 4. Group-focused transformational leadership & 3.85 & .37 & $.62 * *$ & $.38 * *$ & $.30^{*}$ & - & & \\
\hline $\begin{array}{l}\text { 5. Average individual creativity } \times \\
\text { Group-focused transformational leadership }\end{array}$ & .06 & .17 & $27^{*}$ & .16 & $.40^{* *}$ & .24 & - & \\
\hline 6. Team creativity & 3.72 & .65 & $.33 * *$ & $.31 *$ & $.43^{* *}$ & .22 & $.34 * *$ & - \\
\hline
\end{tabular}

Note: $N=64 ;{ }^{*} p \leq .05 . * * p \leq .01$. 
Table 4

Unstandardized Coefficients of the Path Analysis in Study 2

\begin{tabular}{|c|c|c|c|c|c|c|c|c|c|}
\hline & \multicolumn{3}{|c|}{ Average Creative Self-Efficacy } & \multicolumn{3}{|c|}{ Average Individual Creativity } & \multicolumn{3}{|c|}{ Team Creativity } \\
\hline & Estimate & $S E$ & $p$ & Estimate & $S E$ & $p$ & Estimate & $S E$ & $p$ \\
\hline \multicolumn{10}{|l|}{ Model 1: Mediation model } \\
\hline Intercept & .05 & .64 & .94 & .00 & .07 & 1.00 & $3.72 * * *$ & .05 & .00 \\
\hline Shared leadership & $.29 * *$ & .10 & .00 & $.26^{+}$ & .15 & .08 & .23 & .26 & .36 \\
\hline Average creative self-efficacy & & & & $.35^{*}$ & .14 & .02 & .23 & .16 & .14 \\
\hline Average individual creativity & & & & & & & $.41^{+}$ & .21 & .06 \\
\hline Individual-focused TFL & -.01 & .16 & .94 & & & & & & \\
\hline Group-focused TFL & & & & & & & -.07 & .27 & .80 \\
\hline$R^{2}$ & $.17^{*}$ & .08 & .05 & $.18^{*}$ & .07 & .02 & $.24^{+}$ & .13 & .06 \\
\hline \multicolumn{10}{|c|}{ Model 2: Moderated mediation model } \\
\hline Intercept & -.04 & .52 & .94 & .00 & .07 & 1.00 & $3.72 * * *$ & .05 & .00 \\
\hline Shared leadership & $.30 * * *$ & .08 & .00 & $.26^{+}$ & .15 & .08 & .21 & .25 & .40 \\
\hline Average CSE & & & & $.35^{*}$ & .14 & .02 & .24 & .16 & .13 \\
\hline Average individual creativity & & & & & & & .33 & .20 & .11 \\
\hline Individual-focused TFL & .01 & .13 & .94 & & & & & & \\
\hline Group-focused TFL & & & & & & & -.10 & .26 & .71 \\
\hline $\begin{array}{l}\text { Shared leadership } \times \\
\text { Individual-focused TFL }\end{array}$ & $.69 * * *$ & .15 & .00 & & & & & & \\
\hline $\begin{array}{l}\text { Average individual creativity } \times \\
\text { Groun-focused TFL }\end{array}$ & & & & & & & $.67^{*}$ & .32 & .03 \\
\hline$R^{2}$ & $.30 * * *$ & .08 & .00 & $.18^{* *}$ & .07 & .01 & $.25^{*}$ & .11 & .03 \\
\hline
\end{tabular}

Note: ${ }^{+} \mathrm{p} \leq .10$ (two-tailed). ${ }^{*} p \leq .05$ (two-tailed). $* * p \leq .01$ (two-tailed). 
Table 5

Bootstrap Estimation of Monte Carlo Confidence Intervals for the Moderated Mediation Relationships in Study 2

\begin{tabular}{|c|c|c|c|}
\hline \multicolumn{2}{|c|}{ Moderators } & \multirow{2}{*}{$\begin{array}{c}\text { Indirect Effect } \\
(\text { Shared Leadership } \rightarrow \text { Average CSE } \rightarrow \text { Average IC } \rightarrow \text { TC) }\end{array}$} & \multirow[t]{2}{*}{$95 \% \mathrm{CI}$} \\
\hline Individual-focused TFL & Group-focused TFL & & \\
\hline \multirow{3}{*}{ Low (1 sd below mean) } & Low (1 sd below mean) & .001 & {$[-.017, .022]$} \\
\hline & Average (mean) & .004 & {$[-.022, .038]$} \\
\hline & High (1 sd above mean) & .007 & {$[-.039, .061]$} \\
\hline \multirow{3}{*}{ Average (mean) } & Low (1 sd below mean) & .008 & {$[-.046, .070]$} \\
\hline & Average (mean) & .041 & {$[-.002, .131]$} \\
\hline & High ( 1 sd above mean) & .060 & {$[.004, .156]$} \\
\hline \multirow{3}{*}{ High ( 1 sd above mean) } & Low (1 sd below mean) & .015 & {$[-.086, .128]$} \\
\hline & Average (mean) & .064 & {$[-.013, .190]$} \\
\hline & High ( 1 sd above mean) & .113 & {$[.007, .285]$} \\
\hline
\end{tabular}

Note: Average CSE = Average creative self-efficacy; Average IC = Average individual creativity. 
Figure 1

Theoretical Model

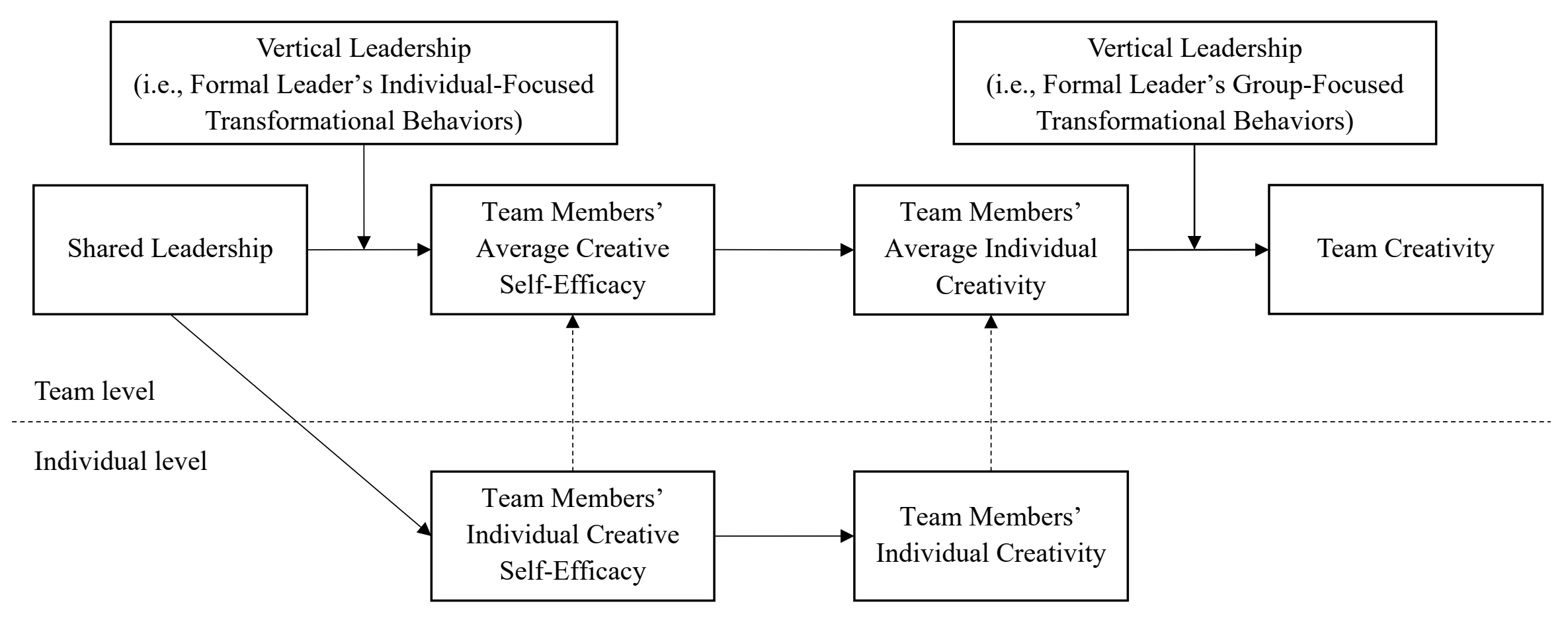




\section{SHARED LEADERSHIP AND TEAM CREATIVITY 62}

Figure 2

Interactive Effect of Individual-focused TFL and Shared leadership on Average Creative Self-efficacy

$-\bullet$ - Low Individual-focused TFL

$\rightarrow-H i g h$ Individual-focused TFL

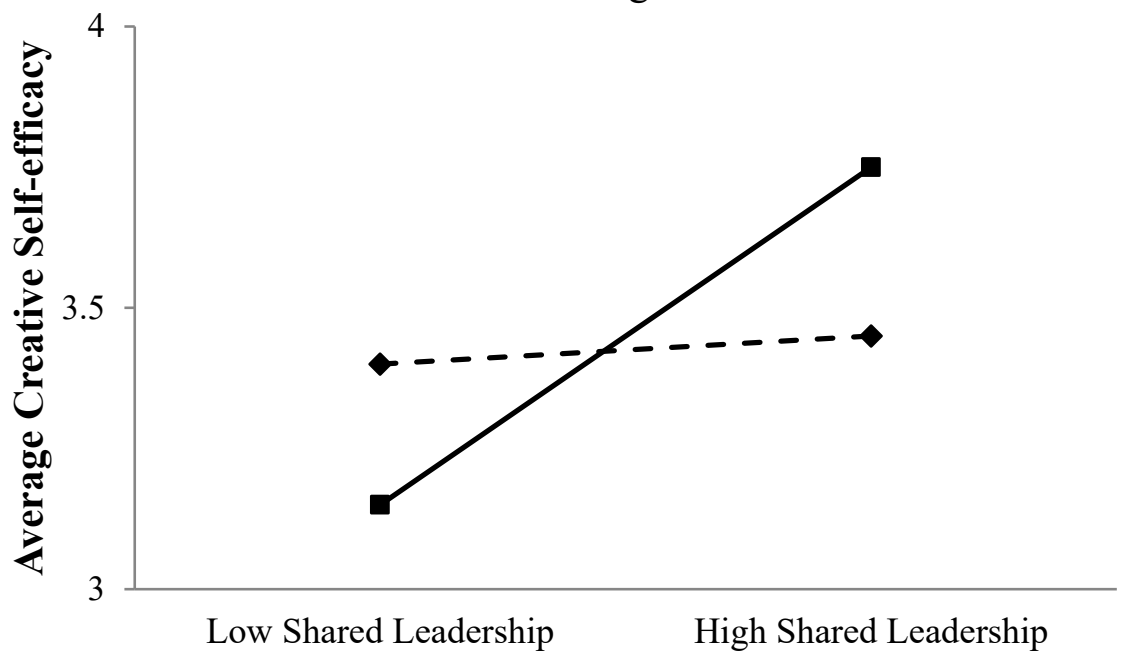




\section{SHARED LEADERSHIP AND TEAM CREATIVITY 63}

Figure 3

Interactive Effect of Group-focused TFL and Average Individual Creativity on Team Creativity

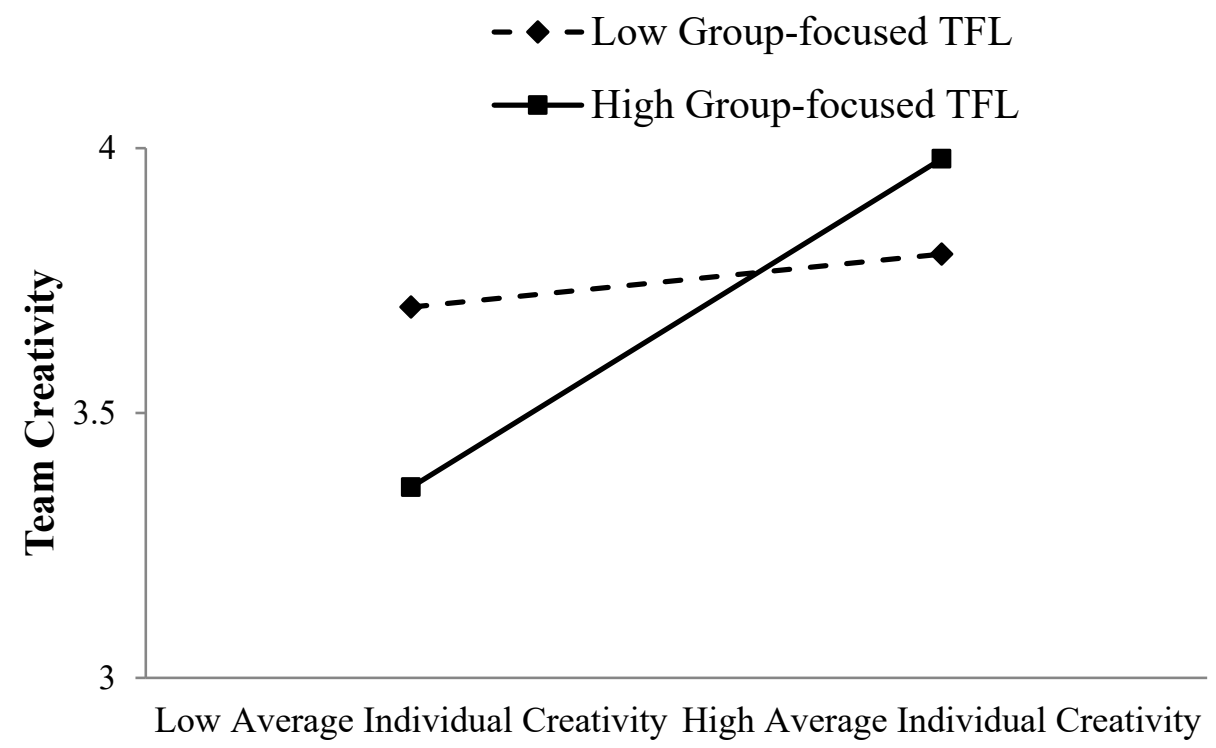




\section{Appendix}

The phenomenon in which multiple team members take on leadership roles to influence others when appropriate to achieve the team's collective goals may be quite prevalent in organizations in today's business world. Please recall the daily social interactions among your team members and evaluate the frequency $(1=$ never; $7=$ always) of your team members sharing in the leadership roles/functions that are described in the following items:

\section{Planning and organizing}

1. How often do your team members plan how the work gets done?

2. How often do your team members allocate team resources according to your team's priorities?

3. How often do your team members set your team's goals?

4. How often do your team members organize tasks so that work flows more smoothly?

5. How often do your team members decide how to go about your team's work?

6. How often do your team members provide helpful input about your team's work-related plans?

\section{Problem solving}

7. How often do your team members decide on the best course of action when a problem arises?

8. How often do your team members diagnose problems quickly?

9. How often do your team members use your team's combined expertise to solve problems?

10. How often do your team members find solutions to problems that affect team performance?

11. How often do your team members identify problems before they arise?

12. How often do your team members develop solutions to problems?

13. How often do your team members solve problems as they arise?

\section{Support and consideration}

14. How often do your team members provide support to team members who need help?

15. How often do your team members show patience toward other team members?

16. How often do your team members encourage other team members when they're upset?

17. How often do your team members listen to the complaints and problems of other team members?

18. How often do your team members foster a cohesive team atmosphere?

19. How often do your team members treat each other with courtesy?

\section{Developing and mentoring}

20. How often do your team members exchange career-related advice?

21. How often do your team members help to develop each other's skills?

22. How often do your team members learn skills from all other team members?

23. How often do your team members be positive role models to new members of the team?

24. How often do your team members instruct poor performers on how to improve?

25 . How often do your team members help out when another team member is learning a new skill? 